\title{
HIGH TEMPERATURE STRENGTH OF REFRACTORY COMPLEX CONCENTRATED ALLOYS
}

O.N. Senkov ${ }^{1, *}$, S. Gorsse ${ }^{2}$ and D.B. Miracle ${ }^{1}$

${ }^{1}$ Air Force Research Laboratory, Materials and Manufacturing Directorate, Wright-Patterson AFB, OH 45433, USA

${ }^{2}$ Université de Bordeaux, CNRS, Bordeaux INP, ICMCB, UMR 5026, F-33600 Pessac, France

*Corresponding author. Email: oleg.senkov.ctr@us.af.mil

\begin{abstract}
Thermodynamic and mechanical properties of 15 single-phase and 11 multi-phase refractory complex concentrated alloys (RCCAs) are reported. Using the CALPHAD approach, phase diagrams for these alloys are calculated to identify the solidus (melting, $T_{\mathrm{m}}$ ) temperatures and volume fractions of secondary phases. Correlations were identified between the strength drops at $1000^{\circ} \mathrm{C}$ and $1200^{\circ} \mathrm{C}$ and the alloy compositions, room temperature properties, melting temperatures and volume fractions of secondary phases. The influence of alloy density on the temperature dependence of specific yield strength was also explored. The conducted analysis suggests that the loss of high-temperature strength of single-phase BCC RCCAs is related to the activation of diffusion-controlled deformation mechanisms, which occurs at $\mathrm{T} \geq 0.6 T_{\mathrm{m}}$, so that the alloys with higher $T_{\mathrm{m}}$ retain their strength to higher temperatures. On the other hand, a rapid decrease in strength of multi-phase RCCAs with increasing temperature above $1000^{\circ} \mathrm{C}$ is probably due to dissolution of secondary phases.
\end{abstract}

Keywords: Refractory alloys; mechanical properties; high temperature strength; CALPHAD. 


\section{INTRODUCTION}

Refractory complex concentrated alloys (RCCAs) have recently brought much attention as promising candidates for high-temperature structural applications, beyond Ni-based superalloys [1-3]. An RCCA, which is also called refractory multi-principal element alloy (RMPEA), consists of three or more principal elements and it may also contain non-principal elements, which are generally added to further improve/optimize properties of the principal composition. Refractory high entropy alloys (RHEAs), which, by definition, contain five or more principal elements with concentrations of each principal element between 5 and 35 at\%, are a sub-class of RCCAs. While RHEAs, because of their high configurational entropy, are sometimes considered to be single-phase, disordered solid solution alloys, RCCAs expand this vast range of new alloys by including multi-phase alloys. RHEAs were first introduced in 2010 [4] and immediately attracted attention due to their ability to retain high strength at temperatures beyond $1000^{\circ} \mathrm{C}$, and in some cases up to $1600^{\circ} \mathrm{C}[1,5]$. In the following years the number of newly reported RCCAs has increased steadily, exceeding 180 by the end of 2018. An extensive review of these alloys and their properties has recently been given $[1,2,6,7]$.

It is well known that metallic alloys generally show a considerable decrease in strength at temperatures above about $0.6 T_{\mathrm{m}}$, where $T_{\mathrm{m}}$ is the absolute melting point. Increasing $T_{\mathrm{m}}$ may therefore increase the maximum operating temperature. Thus refractory metals and alloys with extremely high melting points can be potential candidates for applications at temperatures significantly above Ni-based superalloys. High brittle-to-ductile transition temperature, inferior oxidation resistance and high density limit the applications of many conventional refractory alloys based on a single element. The RCCA concept provides much higher flexibility for the selection of alloy compositions for improved properties. In particular, RCCAs with reduced densities (down to $5.5 \mathrm{~g} / \mathrm{cm}^{3}$ ), considerably improved oxidation resistance and improved room temperature ductility and processability have been identified [1].

More than half of the reported RCCAs are single-phase BCC structures. The matrix phase of multi-phase RCCAs has a BCC or B2 crystal structure and the secondary phases are primarily BCC, B2, Laves, silicides or their combination [1]. Due to the large variations in the compositions, phase content, microstructures and preparation/processing methods, reported RCCAs show quite a large range of mechanical properties $[1,2,6]$. For example, the yield strengths of reported RCCAs fall in the range of $400 \mathrm{MPa}$ to $2612 \mathrm{MPa}$ at $25^{\circ} \mathrm{C}, 40 \mathrm{MPa}$ to 935 
$\mathrm{MPa}$ at $1000^{\circ} \mathrm{C}$ and $24 \mathrm{MPa}$ to $979 \mathrm{MPa}$ at $1200^{\circ} \mathrm{C}$ [6]. Multi-phase RCCAs are generally stronger at room temperature (RT) but they lose their strength more rapidly with increasing temperature as compared to single-phase RCCAs [1]. As a result, single-phase RCCAs become stronger than many multi-phase RCCAs at $\mathrm{T} \geq 1000^{\circ} \mathrm{C}$. For each of these two alloy categories, the temperature-dependent drops in strength are also composition/microstructure dependent. The reasons for such behaviors are currently not identified. The purpose of the present work is to evaluate the influence of alloy melting temperature and the volume fraction of second phases on the temperature dependence of RCCA yield strength. To explore these effects, we analyze the behavior of 15 single-phase and 11 multi-phase RCCAs for which the mechanical properties at room temperature (RT), $1000^{\circ} \mathrm{C}$ and $1200^{\circ} \mathrm{C}$ have been reported [1, 6]. Using the CALPHAD approach, we calculate phase diagrams for these same alloys to identify the melting $\left(T_{\mathrm{m}}\right)$ temperatures, volume fractions of secondary phases and the solvus temperatures $\left(T_{\mathrm{s}}\right)$ at which the secondary phases dissolve in the multi-phase RCCAs studied here. We then explore correlations between the strength drops at $1000^{\circ} \mathrm{C}$ and $1200^{\circ} \mathrm{C}$, the alloy compositions, melting temperatures and volume fractions of secondary phases and analyze the results. We also explore the influence of alloy density on the temperature dependence of specific yield strength. Finally, based on this analysis we make several conclusions, which may be useful for the future development of hightemperature RCCAs.

\section{METHODS}

15 single-phase RCCAs and 11 multi-phase RCCAs, for which compression properties at RT, $1000^{\circ} \mathrm{C}$ and $1200^{\circ} \mathrm{C}$ have been reported in the open literature or acquired by the authors, have been selected for this study. These alloys are drawn from a palette of 12 elements (Al, Cr, Hf, $\mathrm{Mo}, \mathrm{Nb}, \mathrm{Re}, \mathrm{Si}, \mathrm{Ta}, \mathrm{Ti}, \mathrm{V}, \mathrm{W}$, and Zr). They were prepared by mixing and arc-melting highpurity elements followed by solidification on a copper hearth. The compositions of these alloys and their yield strength values are given in Table 1. Nine alloys were in the as-solidified (AC) condition and seventeen alloys were in the annealed (A) condition. For fourteen alloys, hot isostatic pressing (HIP) preceded the annealing step. In spite of different processing conditions, all the studied alloys had coarse-grained structure, with the average grain size exceeding $100 \mu \mathrm{m}$. At such large grain sizes the grain boundary effects on the yield strength and its temperature dependence are considered to be negligible in comparison with solid-solution and precipitation 
strengthening [8-10]. Therefore, grain boundary (Hall-Petch) strengthening is not discussed in this work.

Table 1. Composition, processing condition, phase content, density and yield strength, determined at $23^{\circ} \mathrm{C}, 1000^{\circ} \mathrm{C}$ and $1200^{\circ} \mathrm{C}$, of selected RCCAs. Data are taken from [1] and from the present work.

\begin{tabular}{|c|c|c|c|c|c|c|}
\hline Alloy & Condition $^{\#}$ & Phases & $\begin{array}{l}\text { Density } \\
\mathrm{g} / \mathrm{cm}^{3}\end{array}$ & $\begin{array}{l}\text { YS at } 23^{\circ} \mathrm{C} \\
(\mathrm{MPa})\end{array}$ & $\begin{array}{c}\mathrm{YS} \text { at } 1000^{\circ} \mathrm{C} \\
(\mathrm{MPa})\end{array}$ & $\begin{array}{c}\text { YS at } 1200^{\circ} \mathrm{C} \\
(\mathrm{MPa})\end{array}$ \\
\hline \multicolumn{7}{|c|}{ Reported single-phase alloys } \\
\hline $\mathrm{Al}_{0.4} \mathrm{Hf}_{0.6} \mathrm{NbTaTiZr}$ & $\mathrm{HIP}+\mathrm{A}$ & $\mathrm{BCC}$ & 9.08 & 1841 & 298 & 89 \\
\hline AlCrMoTi & $\mathrm{A}$ & $\mathrm{BCC}$ & 5.98 & 1100 & 375 & 100 \\
\hline AlMoNbTi & A & $\mathrm{BCC}$ & 6.46 & 1100 & 540 & 200 \\
\hline $\mathrm{HfMo}_{0.5} \mathrm{NbTiV}_{0.5}$ & $\mathrm{AC}$ & BCC & 8.96 & 1260 & 368 & 60 \\
\hline HfMoNbTaTiZr & $\mathrm{AC}$ & $\mathrm{BCC}$ & 9.93 & 1512 & 814 & 556 \\
\hline HfMoNbTiZr & $\mathrm{AC}$ & $\mathrm{BCC}$ & 8.68 & 1575 & 635 & 187 \\
\hline HfMoTaTiZr & $\mathrm{AC}$ & $\mathrm{BCC}$ & 10.18 & 1600 & 855 & 404 \\
\hline HfNbTaTiZr & $\mathrm{HIP}+\mathrm{A}$ & $\mathrm{BCC}$ & 9.89 & 929 & 295 & 92 \\
\hline MoNbTaTiVW & $\mathrm{AC}$ & $\mathrm{BCC}$ & 10.91 & 1515 & 753 & 659 \\
\hline MoNbTaTiW & $\mathrm{AC}$ & $\mathrm{BCC}$ & 11.72 & 1343 & 620 & 586 \\
\hline MoNbTaVW & $\mathrm{HIP}+\mathrm{A}$ & $\mathrm{BCC}$ & 12.29 & 1246 & 842 & 735 \\
\hline MoNbTaW & $\mathrm{HIP}+\mathrm{A}$ & $\mathrm{BCC}$ & 13.6 & 996 & 548 & 506 \\
\hline MoNbTi & $\mathrm{HIP}+\mathrm{A}$ & $\mathrm{BCC}$ & 7.67 & 1100 & 504 & 324 \\
\hline $\mathrm{NbTa}_{0.3} \mathrm{TiZr}$ & $\mathrm{HIP}+\mathrm{A}$ & BCC & 7.81 & 882 & 274 & 102 \\
\hline NbTiZr & $\mathrm{HIP}+\mathrm{A}$ & $\mathrm{BCC}$ & 6.63 & 975 & 141 & 61 \\
\hline \multicolumn{7}{|c|}{ Reported multi-phase alloys } \\
\hline AlCrMoNbTi & $\mathrm{A}$ & BCC+Laves & 6.56 & 1010 & 550 & 105 \\
\hline $\mathrm{Al}_{0.24} \mathrm{NbTiVZr}$ & $\mathrm{HIP}+\mathrm{A}$ & BCC+Laves & 6.34 & 1240 & 82 & 24 \\
\hline $\mathrm{AlMo}_{0.5} \mathrm{NbTa}_{0.5} \mathrm{TiZr}$ & $\mathrm{HIP}+\mathrm{A}$ & $\mathrm{B} 2+\mathrm{BCC}+\mathrm{Al}_{4} \mathrm{Zr}_{5}$ & 7.14 & 2000 & 745 & 250 \\
\hline $\mathrm{Cr}_{0.3} \mathrm{NbTiZr}$ & $\mathrm{HIP}+\mathrm{A}$ & BCC+Laves & 6.56 & 1576 & 139 & 32 \\
\hline $\mathrm{CrMo}_{0.5} \mathrm{NbTa}_{0.5} \mathrm{TiZr}$ & $\mathrm{HIP}+\mathrm{A}$ & BCC+BCC+Laves & 7.98 & 1595 & 546 & 170 \\
\hline $\mathrm{HfMo}_{0.5} \mathrm{NbSi}_{0.3} \mathrm{TiV}_{0.5}$ & $\mathrm{AC}$ & $\mathrm{BCC}+\mathrm{M}_{5} \mathrm{Si}_{3}$ & 8.46 & 1617 & 398 & 166 \\
\hline $\mathrm{HfMo}_{0.5} \mathrm{NbSi}_{0.5} \mathrm{TiV}_{0.5}$ & $\mathrm{AC}$ & $\mathrm{BCC}+\mathrm{M}_{5} \mathrm{Si}_{3}$ & 8.16 & 1787 & 614 & 188 \\
\hline $\mathrm{HfMo}_{0.5} \mathrm{NbSi}_{0.7} \mathrm{TiV}_{0.5}$ & $\mathrm{AC}$ & $\mathrm{BCC}+\mathrm{M}_{5} \mathrm{Si}_{3}$ & 7.89 & 2134 & 673 & 235 \\
\hline MoNbTiVZr & $\mathrm{HIP}+\mathrm{A}$ & BCC+Laves & 7.27 & 1706 & 467 & 116 \\
\hline $\mathrm{NbRe}_{0.3} \mathrm{TiZr}$ & $\mathrm{HIP}+\mathrm{A}$ & BCC+Laves & 7.81 & 1244 & 323 & 89 \\
\hline NbTaTiVZr & $\mathrm{HIP}+\mathrm{A}$ & $\mathrm{BCC}+\mathrm{BCC}$ & 8.43 & 1395 & 190 & 78 \\
\hline
\end{tabular}

\# Hot isostatic pressing (HIP), Annealed (A), As-cast (AC)

Phase diagrams for the studied alloys were calculated using the CALPHAD approach. We used ThermoCalc software and the TCHEA3-2018 thermodynamic database developed by ThermoCalc $[11,12]$ and Pandat software (version 2018) and the PanNb2018a database 
developed by CompuTherm, LLC [13, 14] for the calculations. The TCHEA3-2018 database contains 26 elements (Al, B, C, Co, Cr, Cu, Fe, Hf, Ir, Mn, Mo, N, Nb, Ni, Re, Rh, Ru, Si, Sn, Ta, Ti, V, W, Y, Zn, and Zr). All binary systems and 25 ternary systems from the 12-elements included in this study are assessed to their full range of composition in this database. The PanNb2018a database contains 13 elements (Al, Cr, Fe, Hf, Mo, Nb, Re, Si, Ta, Ti, V, W, and $\mathrm{Zr}$ ) and 135 phases. It has complete thermodynamic descriptions for all the binary systems and 34 ternary systems, among which 21 are related to the alloy systems explored in this work.

\section{RESULTS}

\subsection{Calculation of Phase Diagrams of the Studied Alloys}

The level of correctness of the phase diagram calculations and the respective thermodynamic properties directly depend on the level of development of the used thermodynamic database. The calculation for a given alloy is considered to be the most reliable if the database has complete thermodynamic descriptions for all binary and ternary systems included in that alloy [15]. Both the PanNb2018a and TCHEA3-2018 have complete descriptions of the binary systems, but only few of the ternary systems related to the studied alloys are assessed. When the ternary systems are unavailable, thermodynamic calculations are extrapolated from the binary systems [16-18], and such calculations should be treated with caution [17-19]. The credibility of CALPHAD calculations increases with an increase in the fractions of the fully assessed ternary (FAT) systems. FAT is calculated as the ratio of the number of fully assessed ternaries for a given alloy system to the total number of ternaries in that alloy system [15]. FAT values for each of the studied alloys in the PanNb2018a and TCHEA3-2018 databases are given in Table 2. The PanNb2018a database has higher FAT values for 21 of the 26 studied alloys, while TCHEA32018 has higher credibility for only two alloys, AlCrMoTi and AlCrMoNbTi. Both databases have the same credibility for 3 alloys, AlMoNbTi, $\mathrm{CrMo}_{0.5} \mathrm{NbTa}_{0.5} \mathrm{TiZr}$ and MoNbTaW. Nevertheless, for completeness, both databases were used to calculate phase diagrams for all the studied alloys and the results are compared with the available experimental data. The calculated phase diagrams are given in Supplementary Materials. The calculated solidus $\left(T_{\mathrm{m}}\right)$ and solvus ( $T_{\mathrm{s}}$ ) temperatures, as well as solid phases at $T_{\mathrm{m}}$ and a $T_{\mathrm{s}}$-phase, are given in Table 2. $T_{\mathrm{s}}$ is identified as the highest phase transition temperature before melting, and the $T_{\mathrm{s}}$-phase is a phase which dissolves at $T_{\mathrm{s}}$ upon heating. 
Table 2. Fractions of the assessed ternary systems (FAT) in PanNb2018a (Pan) and TCHEA32018 (TC) databases for the studied alloys. Also shown for both databases are the solidus $\left(T_{\mathrm{m}}\right)$ and solvus $\left(T_{\mathrm{s}}\right)$ temperatures; the phases present at $T_{\mathrm{m}}$; the phase related to $T_{\mathrm{s}}$; and $T_{\mathrm{m}}$ calculated using the rule of mixtures (ROM). Preferred calculated values are shown in bold font (see Sec. 3.1.1).

\begin{tabular}{|c|c|c|c|c|c|c|c|c|c|c|c|}
\hline Alloy & $\begin{array}{l}\text { FAT } \\
\text { Pan }\end{array}$ & $\begin{array}{l}\text { FAT } \\
\text { TC }\end{array}$ & \begin{tabular}{|c|}
$T_{\mathrm{m}},{ }^{\circ} \mathrm{C}$ \\
Pan
\end{tabular} & $\begin{array}{c}T_{\mathrm{m}},{ }^{\circ} \mathrm{C} \\
\text { TC }\end{array}$ & $\begin{array}{l}T_{\mathrm{m}},{ }^{\circ} \mathrm{C} \\
\text { ROM } \\
\end{array}$ & $\begin{array}{c}\text { Phases at } T_{m} \\
\text { Pan }\end{array}$ & $\begin{array}{c}\text { Phases at } T_{m} \\
\text { TC }\end{array}$ & $\begin{array}{c}T_{\mathrm{S}},{ }^{\circ} \mathrm{C} \\
\operatorname{Pan}\end{array}$ & \begin{tabular}{|c|}
$T_{\mathrm{S}},{ }^{\circ} \mathrm{C}$ \\
$\mathrm{TC}$
\end{tabular} & $\begin{array}{c}T_{\mathrm{S}} \text {-phase } \\
\text { Pan }\end{array}$ & $\begin{array}{c}T_{\mathrm{S}} \text {-phase } \\
\text { TC }\end{array}$ \\
\hline \multicolumn{12}{|c|}{ Reported single-phase alloys } \\
\hline $\mathrm{Al}_{0.4} \mathrm{Hf}_{0.6} \mathrm{NbTaTiZr}$ & 0.3 & 0.15 & 1732 & 1632 & 2124 & $\mathrm{BCC} 1$ & BCC1 & 1636 & 1356 & BCC2 & BCC2 \\
\hline AlCrMoTi & 0 & 1 & 1663 & 1876 & 1715 & BCC1 & BCC & 975 & 931 & A15 & A15 \\
\hline AlMoNbTi & 0.5 & 0.5 & 1959 & 1780 & 1857 & BCC1 & BCC & 846 & 1143 & A15 & $\mathbf{A 1 5}$ \\
\hline $\mathrm{HfMo}_{0.5} \mathrm{NbTiV}_{0.5}$ & 0.2 & 0 & 1987 & 1776 & 2161 & BCC1 & $\mathrm{BCC} 1$ & 724 & 827 & $\overline{\text { BCC2 }}$ & BCC2 \\
\hline HfMoNbTaTiZr & 0.3 & 0 & 1860 & 1840 & 2312 & BCC1 & BCC1 & 1507 & 1171 & $\mathrm{BCC} 2$ & BCC2 \\
\hline HfMoNbTiZr & 0.3 & 0 & 1844 & 1767 & 2171 & BCC1 & BCC1 & 917 & 1038 & BCC2 & BCC2 \\
\hline HfMoTaTiZr & 0.1 & 0 & 1723 & 1793 & 2279 & $\mathrm{BCC} 1+\mathrm{BCC} 2$ & BCC1 & 906 & 1168 & $\mathrm{HCP}$ & BCC2 \\
\hline HfNbTaTiZr & 0.5 & 0 & 1882 & 1851 & 2250 & BCC1 & BCC1 & 984 & 1019 & BCC2 & $\mathrm{BCC} 2$ \\
\hline MoNbTaTiVW & 0.2 & 0 & 2182 & 2296 & 2520 & BCC1 & $\mathrm{BCC}$ & 846 & 572 & BCC2 & $\mathrm{HCP}$ \\
\hline MoNbTaTiW & 0.3 & 0 & 2395 & 2416 & 2641 & BCC1 & BCC1 & 1100 & 708 & $\mathrm{BCC} 2$ & BCC2 \\
\hline MoNbTaVW & 0.1 & 0 & 2409 & 2566 & 2690 & BCC1 & BCC1 & 824 & 410 & BCC2 & BCC2 \\
\hline MoNbTaW & 0 & 0 & 2807 & 2804 & 2885 & BCC & $\mathrm{BCC}$ & $*$ & * & * & * \\
\hline MoNbTi & 1 & 0 & 2115 & 1970 & 2256 & BCC1 & $\mathrm{BCC} 1$ & 740 & 781 & $\mathrm{BCC} 2$ & $\mathrm{BCC} 2$ \\
\hline $\mathrm{NbTa}_{0.3} \mathrm{TiZr}$ & 0.75 & 0 & 1711 & 1727 & 2092 & BCC1 & BCC1 & 850 & 831 & BCC2 & BCC2 \\
\hline NbTiZr & 1 & 0 & 1688 & 1691 & 2000 & BCC1 & BCC1 & 600 & 694 & $\mathrm{BCC} 2$ & $\mathrm{BCC} 2$ \\
\hline \multicolumn{12}{|c|}{ Reported multi-phase alloys } \\
\hline AlCrMoNbTi & 0.5 & 0.8 & 1721 & 1780 & 1867 & $\mathrm{BCC} 1$ & BCC1 & 840 & 1534 & $\mathrm{C} 14$ & C14 \\
\hline $\mathrm{Al}_{0.24} \mathrm{NbTiVZr}$ & 0.2 & 0.1 & 1545 & 1491 & 1903 & BCC1 & $\mathrm{BCC} 1$ & 887 & 863 & BCC2 & BCC2 \\
\hline $\mathrm{AlMo}_{0.5} \mathrm{NbTa}_{0.5} \mathrm{TiZr}$ & 0.3 & 0.25 & 1595 & 1478 & 1896 & BCC1+BCC2 & $\mathrm{BCC} 1+\mathrm{BCC} 2+\sigma$ & 1197 & 1200 & $\mathbf{A l}_{4} \mathbf{Z r}_{5}$ & $\mathrm{Al}_{4} \mathrm{Zr}_{5}$ \\
\hline $\mathrm{Cr}_{0.3} \mathrm{NbTiZr}$ & 1 & 0.5 & 1465 & 1410 & 1991 & BCC1 & $\mathrm{BCC}$ & 1185 & 1273 & C15 & C15 \\
\hline $\mathrm{CrMo}_{0.5} \mathrm{NbTa}_{0.5} \mathrm{TiZr}$ & 0.45 & 0.45 & 1397 & 1400 & 2145 & BCC1+C15 & $\mathrm{BCC} 1+\mathrm{C} 15$ & 1347 & 1050 & BCC2 & BCC2 \\
\hline $\mathrm{HfMo}_{0.5} \mathrm{NbSi}_{0.3} \mathrm{TiV}_{0.5}$ & 0.35 & 0.2 & 1621 & 1190 & 2109 & $\mathbf{B C C} 1+\mathrm{M}_{5} \mathrm{Si}_{3}$ & $\mathrm{BCC} 1+\mathrm{C} 16$ & 1114 & 750 & $\mathbf{M}_{2} \mathbf{S i}$ & $\mathrm{BCC} 2$ \\
\hline $\mathrm{HfMo}_{0.5} \mathrm{NbSi}_{0.5} \mathrm{TiV}_{0.5}$ & 0.35 & 0.2 & 1630 & 1213 & 2078 & $\mathrm{BCC} 1+\mathrm{M}_{5} \mathrm{Si}_{3}$ & $\begin{array}{l}\mathrm{BCC} 1+\mathrm{C} 16+ \\
\mathrm{M}_{5} \mathrm{Si}_{3}\end{array}$ & 1118 & 690 & $\mathbf{M}_{2} \mathrm{Si}$ & $\mathrm{M}_{3} \mathrm{Si}$ \\
\hline $\mathrm{HfMo}_{0.5} \mathrm{NbSi}_{0.7} \mathrm{TiV}_{0.5}$ & 0.35 & 0.2 & 1642 & 1222 & 2050 & $\mathrm{BCC1}+\mathrm{M}_{5} \mathrm{Si}_{3}$ & $\begin{array}{l}\mathrm{BCCl} 1+\mathrm{C} 16+ \\
\mathrm{M}_{5} \mathrm{Si}_{3}\end{array}$ & 1120 & 620 & $\mathbf{M}_{2} \mathrm{Si}$ & $\mathrm{M}_{3} \mathrm{Si}$ \\
\hline MoNbTiVZr & 0.2 & 0 & 1649 & 1583 & 2107 & BCC1 & BCC1 & 994 & 970 & BCC2 & BCC2 \\
\hline NbRe0.3TiZr & 0.75 & 0.5 & 1704 & 1683 & 2108 & BCC1 & $\mathrm{BCC}$ & 1656 & 933 & C14 & $\operatorname{ReZr}_{2}$ \\
\hline NbTaTiVZr & 0.4 & 0 & 1612 & 1581 & 2185 & BCC1 & BCC1 & 1036 & 942 & BCC2 & BCC2 \\
\hline
\end{tabular}

* No secondary phase is predicted to form for this alloy

Analysis of the calculations show that, for the same alloy, the two databases calculate almost the same $T_{\mathrm{m}}$ values, with the exception of three $\mathrm{Si}$-containing alloys, for which $T_{\mathrm{m}}{ }^{\mathrm{TC}}$ values were considerably lower than $T_{\mathrm{m}}{ }^{\text {Pan }}$ (Figure 1a). The superscripts 'TC' and 'Pan' indicate that the 
quantities were calculated using ThermoCalc or Pandat software, respectively. It is likely that the TC calculations for the Si-containing alloys are incorrect, because they predict melting of these alloys around $1200^{\circ} \mathrm{C}$, while the experimental results revealed that these alloys were solid and showed rather high strength at $1200^{\circ} \mathrm{C}$. With five exceptions, the Pan and TC calculations predict almost the same phases at $T_{\mathrm{m}}$, for each of the studied alloys (Table 2). However, the $T_{\mathrm{s}}$ values calculated with PanNb2018a and TCHEA3-2018 are quite different (Figure 1b). In spite of this, both databases calculate the same $T_{\mathrm{s}}$-phases for each of the studied alloys, with only three exceptions (Table 2).
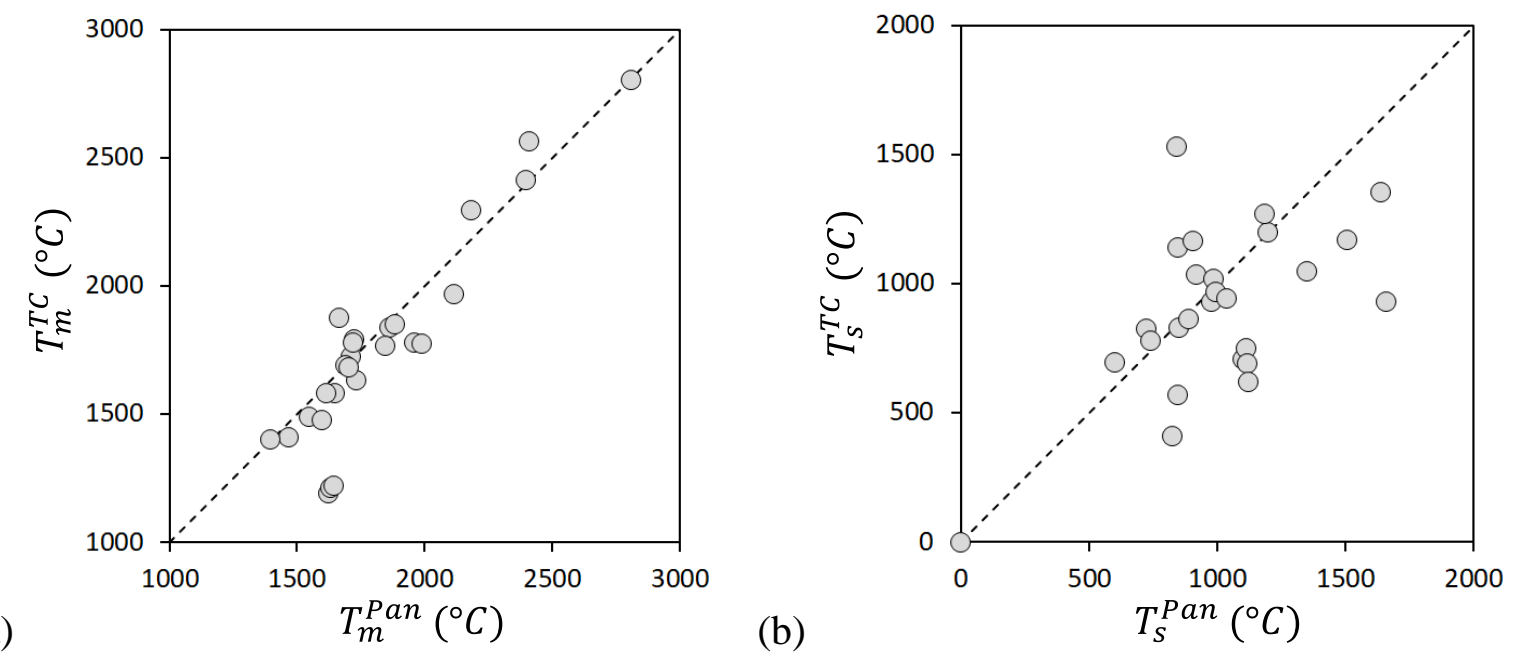

Figure 1. Comparison of (a) solidus $\left(T_{\mathrm{m}}^{\mathrm{Pan}}, T_{\mathrm{m}}^{\mathrm{TC}}\right)$ and (b) solvus $\left(T_{\mathrm{s}}^{\mathrm{Pan}}, T_{\mathrm{s}}^{\mathrm{TC}}\right)$ temperatures calculated with PanNb2018a (Pan) and TCHEA3-2018 (TC) thermodynamic databases.

\subsubsection{Comparison with experiment and CALPHAD calculations selection}

\section{Single-phase RCCAs}

For the 15 RCCAs that are experimentally reported as single-phase BCC structures, both PanNb2018a and TCHEA3-2018 predict single-phase BCC phase field with a large temperature interval between $T_{\mathrm{m}}$ and $T_{\mathrm{s}}$ (Table 2). Formation of equilibrium secondary phases is predicted at temperatures below $1000^{\circ} \mathrm{C}$ in all but one of these alloys. Therefore, the single phase BCC structures observed at room temperature are likely metastable because formation of secondary phases that are thermodynamically stable at room temperature is kinetically restricted by low $T_{\mathrm{s}}$ and slow diffusion. These supersaturated solid solutions may decompose and form secondary phases when heated for sufficient time between $23^{\circ} \mathrm{C}$ and $T_{\mathrm{s}}$. Only one alloy, MoNbTaW, is 
predicted by both databases to be a thermodynamically stable single-phase BCC structure at room temperature.

Comparison of the CALPHAD calculations with experimental results allows identification of a preferred database for each of the studied alloys. First, for $\mathrm{Al}_{0.4} \mathrm{Hf}_{0.6} \mathrm{NbTaTiZr}$ and HfMoNbTaTiZr PanNb2018a predicts formation of a second phase (BCC2) at relatively high temperatures, $T_{\mathrm{s}}=1636^{\circ} \mathrm{C}$ and $1507^{\circ} \mathrm{C}$, respectively. If the calculations are correct, the alloys should be two-phase structures at room temperature, which contradict experiments. On the other hand, TCHEA3-2018 predicts much lower $T_{\mathrm{s}}=1356^{\circ} \mathrm{C}$ and $1171^{\circ} \mathrm{C}$, respectively, for these alloys. Experiments do not show a second phase in the $1200^{\circ} \mathrm{C}$ annealed $\mathrm{Al}_{0.4} \mathrm{Hf}_{0.6} \mathrm{NbTaTiZr}_{20}$ ] and as-cast HfMoNbTaTiZr [21], indirectly indicating that $T_{\mathrm{s}}$ is low enough to restrict the phase transformation kinetically. As a result, TCHEA3-2018 data will be used for these two alloys. Second, PanNb2018a predicts two BCC phases in HfMoTaTiZr after solidification, which disagrees with the experiment. On the other hand, TCHEA3-2018 predicts one BCC phase at $T_{\mathrm{m}}$ and the second $\mathrm{BCC}$ phase forms in equilibrium conditions below $T_{\mathrm{s}}=1168^{\circ} \mathrm{C}$. Therefore, the results from TCHEA3-2018 calculations will be used for HfMoTaTiZr. Finally, MoNbTaTiW has been found experimentally to be a single-phase BCC structure both in the as-cast condition and after annealing at $1200^{\circ} \mathrm{C}$ for $24 \mathrm{~h}$ [22], which agrees better with TCHEA3-2018 than with PanNb2018a calculations (Table 2).

\section{Multi-phase RCCAs}

Eight RCCAs that do not contain Si are reported to be multi-phase after annealing at $1200^{\circ} \mathrm{C}$ or $1400^{\circ} \mathrm{C}$, and $3 \mathrm{Si}$-containing RCCAs are reported as multi-phase in the as-cast condition (Table 1). CALPHAD predictions of the type and number of phases in these alloys (Table 2) agree well with the experimental data. Both PanNb2018a and TCHEA3-2018 databases predict that 5 of these multi-phase RCCAs $\left(\mathrm{AlMo}_{0.5} \mathrm{NbTa}_{0.5} \mathrm{TiZr}_{\mathrm{C}} \mathrm{CrMo}_{0.5} \mathrm{NbTa}_{0.5} \mathrm{TiZr}, \mathrm{HfMo}_{0.5} \mathrm{NbSi}_{0.3} \mathrm{TiV}_{0.5}\right.$, $\mathrm{HfMo}_{0.5} \mathrm{NbSi}_{0.5} \mathrm{TiV}_{0.5}$ and $\mathrm{HfMo}_{0.5} \mathrm{NbSi}_{0.7} \mathrm{TiV}_{0.5}$ ) are not single-phase above $T_{\mathrm{s}}$ and retain a multi-phase structure up to $T_{\mathrm{m}}$. The other 6 RCCAs have a single-phase BCC region above $T_{\mathrm{s}}$; e.g. $\mathrm{Al}_{0.24} \mathrm{NbTiZr}$, MoNbTiVZr and NbTaTiVZr have $T_{\mathrm{s}}$ below $1200^{\circ} \mathrm{C}$, according to both databases, and thus they can be considered as single-phase structures when tested above $T_{\mathrm{s}}$. 


\section{Selection of CALPHAD calculations for mechanical property analysis}

In the analyses conducted in the following sections, CALPHAD calculations that best agree with the reported experimental data are used. When both PanNb2018a and TCHEA3-2018 calculations agree with the experimental results equally well, the calculations with higher FAT values are used. If FAT values are the same, TCHEA3-2018 calculations are used for the alloys which do not contain $\mathrm{Nb}$. The $T_{\mathrm{s}}$ and $T_{\mathrm{m}}$ values and respective phases thus selected are highlighted by a bold font in Table 2 for each of the studied alloys. The superscript 'CALPHAD' or no superscript is used to indicate these preferred values in the remainder of this work.

\subsubsection{Comparison of CALPHAD-calculated and rule-of-mixtures calculated $T_{\mathrm{m}}$}

Figure 2 compares $T_{\mathrm{m}}{ }^{\text {CALPHAD }}$ values for the studied alloys with those calculated using rule of mixtures (ROM):

$$
T_{\mathrm{m}}^{\mathrm{ROM}}=\sum c_{i} T_{m i}
$$

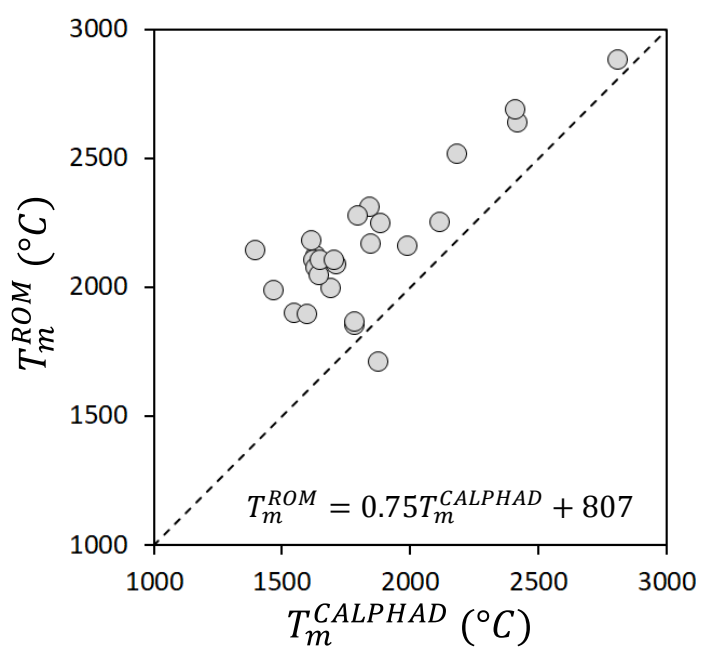

Figure 2. Comparison of the CALPHAD-calculated solidus temperatures $T_{\mathrm{m}}{ }^{\text {CALPHAD }}$ for the studied alloys with those calculated with the use of the rule of mixtures, $T_{\mathrm{m}}{ }^{\mathrm{ROM}}$. The dashed line corresponds to the condition when $T_{\mathrm{m}}{ }^{\mathrm{ROM}}=T_{\mathrm{m}}{ }^{\text {CALPHAD }}$.

Here $c_{\mathrm{i}}$ is the atomic fraction and $T_{\mathrm{mi}}$ is the melting temperature of element $i$. It is found that $T_{\mathrm{m}}{ }^{\mathrm{ROM}}$ is higher than $T_{\mathrm{m}}{ }^{\text {CALPHAD }}$ for almost all the alloys. The difference is generally larger for alloys with lower $T_{\mathrm{m}}$, i.e. for alloys containing $\mathrm{Al}$ and $\mathrm{Cr}$, as well as for multi-phase alloys (Table 2). Thus, the ROM overestimates $T_{\mathrm{m}}$ for the studied RCCAs. Such behavior can be expected 
because ROM predicts a straight solidus line between any two melting points, while in the solidsolution based alloy systems, with no high-temperature compounds, the solidus line always deviates from a straight line towards lower temperatures.

\subsection{Effect of the melting temperature on the strength of RCCAs}

It can be seen from the CALPHAD calculations (Table 2) that the multi-phase RCCAs have relatively low $T_{\mathrm{m}}$, often considerably lower than single-phase RCCAs. Indeed, $T_{\mathrm{m}}$ of the reported multi-phase RCCAs varies from $1397^{\circ} \mathrm{C}$ for $\mathrm{CrMo}_{0.5} \mathrm{NbTa}_{0.5} \mathrm{TiZr}$ to $1780^{\circ} \mathrm{C}$ for $\mathrm{AlCrMoNbTi}$, while $T_{\mathrm{m}}$ of the reported single-phase RCCAs varies from $1632^{\circ} \mathrm{C}$ for $\mathrm{Al}_{0.4} \mathrm{Hf}_{0.6} \mathrm{NbTaTiZr}$ to $2804^{\circ} \mathrm{C}$ for MoNbTaW. Only two single-phase alloys have $T_{\mathrm{m}}$ below $1700^{\circ} \mathrm{C}$, while only two multi-phase alloys have $T_{\mathrm{m}}$ above $1700^{\circ} \mathrm{C}$. The lower melting temperatures can limit operating temperatures of the multi-phase RCCAs relative the single-phase RCCAs. The behavior of these two categories of RCCAs at different temperatures is described in detail in the following sections.

\section{Room temperature (RT) behavior}

There is no clear correlation between $T_{\mathrm{m}}$ and the yield strength of RCCAs at $25^{\circ} \mathrm{C}$ (Figure $3 \mathrm{a}$ ). Single-phase alloys have RT yield strength $\sigma_{0.2}{ }^{25^{\circ} \mathrm{C}}$ in the range from $882 \mathrm{MPa}$ for $\mathrm{NbTa}_{0.3} \mathrm{TiZr}$ $\left(T_{\mathrm{m}}=1711^{\circ} \mathrm{C}\right)$ to $1841 \mathrm{MPa}$ for $\mathrm{Al}_{0.4} \mathrm{Hf}_{0.6} \mathrm{NbTaTiZr}\left(T_{\mathrm{m}}=1632^{\circ} \mathrm{C}\right)$. The RT yield strength of MoNbTaW, which has the highest $T_{\mathrm{m}}\left(=2804^{\circ} \mathrm{C}\right)$, is $996 \mathrm{MPa}$. The multi-phase alloys have, on average, higher RT yield strength than the single-phase alloys (Figure 3a). The $\sigma_{0.2}{ }^{2{ }^{\circ} \mathrm{C}}$ of these alloys is in the range from $1010 \mathrm{MPa}$ for $\mathrm{AlCrMoNbTi}\left(T_{\mathrm{m}}=1780^{\circ} \mathrm{C}\right)$ to $2134 \mathrm{MPa}$ for $\mathrm{HfMo}_{0.5} \mathrm{NbSi}_{0.7} \mathrm{TiV}_{0.5}\left(T_{\mathrm{m}}=1642^{\circ} \mathrm{C}\right)$. Figure $3 \mathrm{~b}$ shows the dependence of $\sigma_{0.2}{ }^{25^{\circ} \mathrm{C}}$ on the atomic radius misfit parameter, $\delta_{\mathrm{r}}$. By definition, $\delta_{r}=100 \% \sqrt{\sum c_{i}\left(1-\frac{r_{i}}{\bar{r}}\right)^{2}}$, where $c_{\mathrm{i}}$ and $r_{\mathrm{i}}$ are the mole fraction and atomic radius of an alloying element $i$, respectively, and $\bar{r}=\sum c_{i} r_{i}$. It can be seen that the single-phase RCCAs have $\delta_{\mathrm{r}}<7.5 \%$ and there is no clear correlation between $\sigma_{0.2}{ }^{2{ }^{\circ} \mathrm{C}}$ and $\delta_{\mathrm{r}}$ for these alloys. The multi-phase RCCAs have $\delta_{\mathrm{r}}$ from 5.3 to $10.2 \%$ and there is a tendency for the alloys containing the Laves and silicide phases to increase $\sigma_{0.2}{ }^{2} \mathrm{C}$ with increasing $\delta_{\mathrm{r}}$. Figure $3 \mathrm{c}$ shows the dependence of $\sigma_{0.2}{ }^{25^{\circ} \mathrm{C}}$ on the experimentally reported volume fraction of all of the secondary phases, $V$, in multi-phase alloys. There is a clear tendency for 
$\sigma_{0.2}{ }^{25^{\circ} \mathrm{C}}$ to increase with an increase in the volume fraction of the secondary phases; however, the alloy chemical composition (i.e. atom interaction forces) is also important. For example, $\mathrm{Al}_{0.24} \mathrm{NbTiVZr}$ and MoNbTiVZr have almost the same volume fraction (36\% and 35\%, respectively) of the secondary Laves phase; however $\sigma_{0.2}{ }^{25^{\circ} \mathrm{C}}$ of the first alloy is $1240 \mathrm{MPa}$ and the second alloy is $1706 \mathrm{MPa}$. This analysis indicates that the higher RT strengths of the multiphase alloys are likely a result of additional strengthening from the multi-phase microstructures and increasing volume fraction of the secondary phases.

(a)
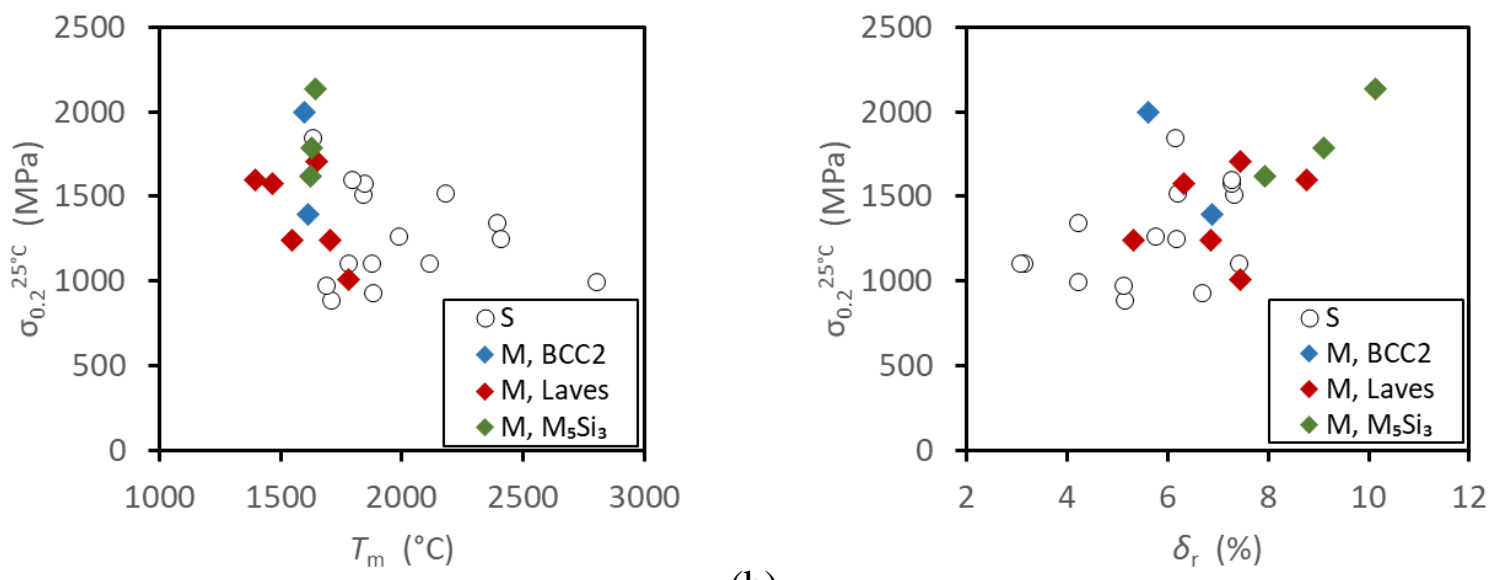

(b)

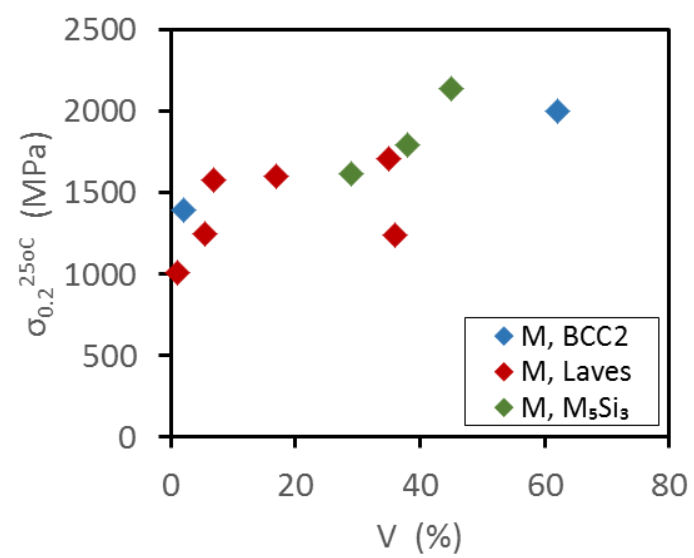

(c)

Figure 3. Room temperature yield strength $\left(\sigma_{0.2}{ }^{25^{\circ} \mathrm{C}}\right)$ of single-phase (S) and multi-phase (M) RCCAs as a function of (a) the alloy melting temperature $T_{\mathrm{m}}$, (b) atomic radius misfit parameter $\delta_{\mathrm{r}}$, and (c) volume fraction (in percent) of the secondary phases. The type of the major secondary phase is shown in the legends. 


\section{Behavior of RCCAs at $1000^{\circ} \mathrm{C}$}

According to CALPHAD calculations and their comparison with the experimental data, the single-phase BCC RCCAs are metastable supersaturated solid solutions at room temperature. Therefore, during heating and holding at a testing temperature $\left(1000^{\circ} \mathrm{C}\right)$ they may experience phase transformations and become multi-phase structures. The diffusion processes required to initiate the phase transformations generally become noticeable at temperatures $T>0.4 T_{\mathrm{m}}$, where $\mathrm{T}_{\mathrm{m}}$ is the absolute melting temperature, while at $T<0.4 T_{\mathrm{m}}$ the phase transformations are kinetically restricted [23]. It is therefore assumed in this work that the single-phase RCCAs with $T_{\mathrm{s}}>1000^{\circ} \mathrm{C}$ and $T_{\mathrm{m}}<2910^{\circ} \mathrm{C}(3183 \mathrm{~K})$ become multi-phase structures during heating and deformation at $1000^{\circ} \mathrm{C}$. Four RCCAs, $\mathrm{Al}_{0.4} \mathrm{Hf}_{0.6} \mathrm{NbTaTiZr}$, AlMoNbTi, HfMoNbTaTiZr and HfMoTaTiZr, satisfy these conditions. Other single-phase RCCAs retain their single-phase structure at $1000^{\circ} \mathrm{C}$. For the same reason, RCCAs that are multi-phase at $25^{\circ} \mathrm{C}$ and also have $T_{\mathrm{S}}$ $\leq 1000^{\circ} \mathrm{C}, T_{\mathrm{m}}<2910^{\circ} \mathrm{C}(3183 \mathrm{~K})$ and a single phase at $T_{\mathrm{m}}$, become single-phase structures at $1000^{\circ} \mathrm{C}$. These are $\mathrm{Al}_{0.24} \mathrm{NbTiVZr}$ and MoNbTiVZr. Other multi-phase RCCAs retain their multi-phase structure at $1000^{\circ} \mathrm{C}$.

Figure 4a shows the dependence of the yield strength at $1000^{\circ} \mathrm{C}\left(\sigma_{0.2}{ }^{1000^{\circ} \mathrm{C}}\right)$ on $T_{\mathrm{m}}$ for singlephase and multi-phase RCCAs. There is clear tendency for single-phase RCCAs to increase in strength at $1000^{\circ} \mathrm{C}$ with increasing $T_{\mathrm{m}}$. For example, alloys with $T_{\mathrm{m}}<1750^{\circ} \mathrm{C}$, between $1750^{\circ} \mathrm{C}$ and $2000^{\circ} \mathrm{C}$ and above $2000^{\circ} \mathrm{C}$ have $\sigma_{0.2}{ }^{1000^{\circ} \mathrm{C}}$ in the range from $141 \mathrm{MPa}$ to $274 \mathrm{MPa}$, from 295 $\mathrm{MPa}$ to $635 \mathrm{MPa}$, and from $504 \mathrm{MPa}$ to $842 \mathrm{MPa}$, respectively. The four RCCAs observed to be single-phase at $25^{\circ} \mathrm{C}$ but predicted by CALPHAD to become multi-phase at $1000^{\circ} \mathrm{C}$ show a trend to increase $\sigma_{0.2}{ }^{1000^{\circ} \mathrm{C}}$ beyond the typical range for single-phase RCCAs with the same $T_{\mathrm{m}}$ values due to additional precipitation-strengthening effect.

The multi-phase RCCAs show no dependence of $\sigma_{0.2}{ }^{1000^{\circ} \mathrm{C}}$ on $T_{\mathrm{m}}$. These alloys have a narrow $T_{\mathrm{m}}$ range and the alloys with almost the same $T_{\mathrm{m}}$ can have quite different $\sigma_{0.2}{ }^{1000^{\circ} \mathrm{C}}$ values ranging from $139 \mathrm{MPa}$ for $\mathrm{Cr}_{0.3} \mathrm{NbTiZr}$ to $745 \mathrm{MPa}$ for $\mathrm{AlMo}_{0.5} \mathrm{NbTa}_{0.5} \mathrm{TiZr}$ (Figure 4a, Table 1). A former multi-phase $\mathrm{Al}_{0.24} \mathrm{NbTiVZr}$, which contains a Laves phase at room temperature and has $\sigma_{0.2}{ }^{25^{\circ} \mathrm{C}}=1240 \mathrm{MPa}$, becomes a single-phase BCC structure with the lowest strength $\left(\sigma_{0.2^{1}}{ }^{1000^{\circ} \mathrm{C}}=\right.$ $82 \mathrm{MPa}$ ) at $1000^{\circ} \mathrm{C}$ among all the reported RCCAs, probably due to its relatively low $T_{\mathrm{m}}=$ $1545^{\circ} \mathrm{C}$ (Figure $4 \mathrm{a}$ ). On the other hand, MoNbTiVZr also becomes single-phase at $1000^{\circ} \mathrm{C}$ but it has a $T_{\mathrm{m}}$ of $\sim 100^{\circ} \mathrm{C}$ higher than the former alloy and retains a relatively high strength of $\sigma_{0.2^{1000^{\circ}} \mathrm{C}}$ 
$=467 \mathrm{MPa}$ at $1000^{\circ} \mathrm{C}$. The behaviors of these two alloys are in line with the behavior of singlephase RCCAs (Figure 4a).
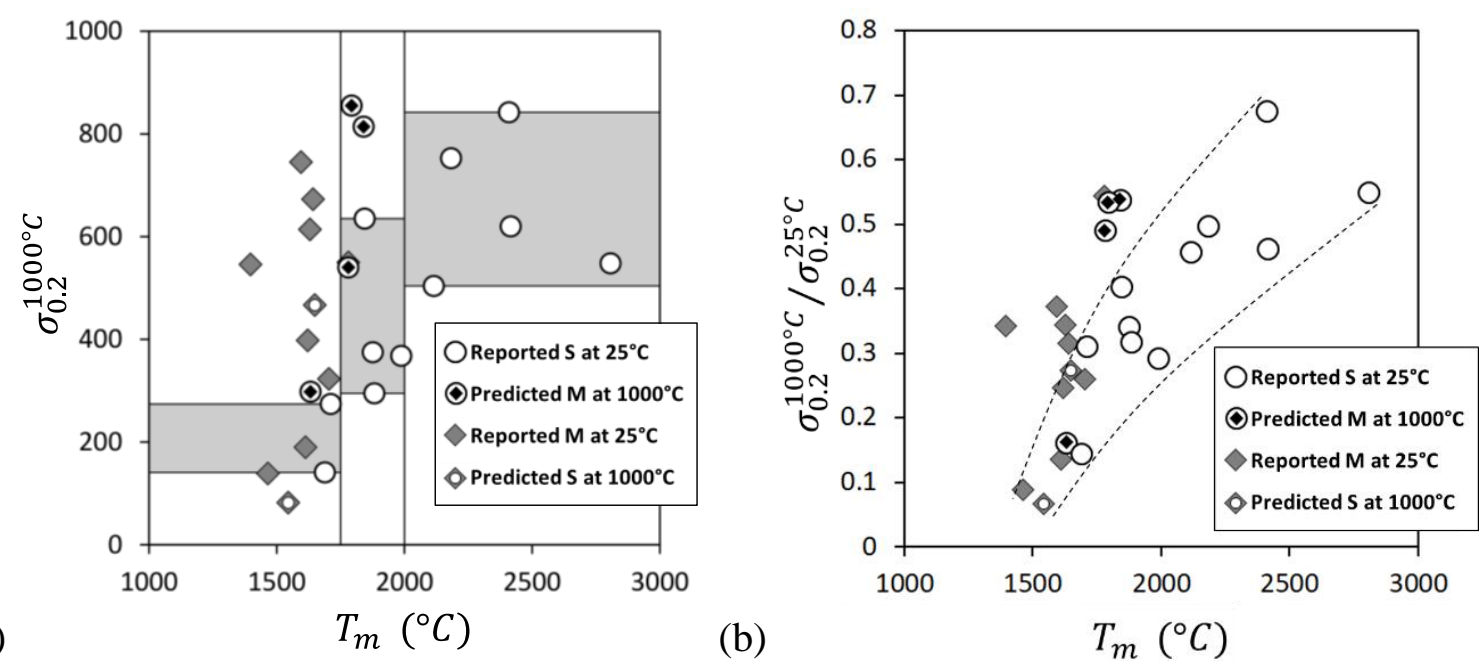

Figure 4. (a) Yield strength at $1000^{\circ} \mathrm{C}\left(\sigma_{0.2}{ }^{1000^{\circ} \mathrm{C}}\right)$ and (b) yield strength ratio $\left(\sigma_{0.2}{ }^{1000^{\circ} \mathrm{C}} / \sigma_{0.2}{ }^{25^{\circ} \mathrm{C}}\right)$ of single-phase (S) and multi-phase (M) RCCAs as a function of the melting temperature $T_{\mathrm{m}}$.

Figure $4 \mathrm{~b}$ compares yield strength values at $1000^{\circ} \mathrm{C}$ and $25^{\circ} \mathrm{C}$ of the single-phase and multiphase RCCAs with different melting temperatures. A strength drop occurs between these temperatures and the magnitude of the drop, $\eta_{1}=\sigma_{0.2}{ }^{1000^{\circ} \mathrm{C}} / \sigma_{0.2}{ }^{25^{\circ} \mathrm{C}}$, strongly depends on the type of alloy. For the single-phase RCCAs, $\eta_{1}$ is the lowest $(=0.07)$ for the $\mathrm{Al}_{0.24} \mathrm{NbTiVZr}$, which has the lowest $T_{\mathrm{m}}=1545^{\circ} \mathrm{C}$. The ratio tends to increase with increasing $T_{\mathrm{m}}$ and approaches $\eta_{1}=0.45$ 0.7 for single-phase alloys with $T_{\mathrm{m}}>2000^{\circ} \mathrm{C}$. On the other hand, the $\eta_{1}$ values for multi-phase RCCAs do not depend on $T_{\mathrm{m}}$ and for alloys with almost the same $T_{\mathrm{m}} \eta_{1}$ varies from 0.09 to 0.54 . Figure 5 shows dependence of $\sigma_{0.2^{1}}{ }^{1000^{\circ} \mathrm{C}}$ of the multi-phase alloys on (a) the volume fraction of the secondary phases $V$ at $1000^{\circ} \mathrm{C}$ and (b) the temperature difference between the solvus, $T_{\mathrm{s}}$, and testing temperatures $\left(\Delta T=T_{\mathrm{s}}-1000^{\circ} \mathrm{C}\right)$. . It can be clearly seen from Figure 5a that the different strength values of multi-phase alloys at $1000^{\circ} \mathrm{C}$ are due to the different volume fractions of the secondary phases. With the same type of secondary phase, $\sigma_{0.2}{ }^{1000^{\circ} \mathrm{C}}$ increases with an increase in $V$. Because $V$ generally decreases with increasing temperature and approaches zero at $T=T_{\mathrm{S}}$, $\sigma_{0.2}{ }^{1000^{\circ} \mathrm{C}}$ tends to increase with increasing $T_{\mathrm{S}}(\Delta T)$, Figure $5 \mathrm{~b}$. Because different alloys have different dependence of $V$ on $\Delta T$, the relationship between $\sigma_{0.2}{ }^{1000^{\circ} \mathrm{C}}$ and $\Delta T$ is not as straightforward as that between $\sigma_{0.2}{ }^{1000^{\circ} \mathrm{C}}$ and $V$, when different multi-phase alloys are 
considered, and the alloys with similar $\Delta T$ may have quite different $\sigma_{0.2}{ }^{1000^{\circ} \mathrm{C}}$ values (compare Figure 5a and Figure 5b).

These results clearly show that the drop in strength between $25^{\circ} \mathrm{C}$ and $1000^{\circ} \mathrm{C}$ is more dramatic for single-phase RCCAs with lower $T_{\mathrm{m}}$ and for multi-phase RCCAs with a stronger temperature dependence of the volume fraction of secondary phases. Single-phase RCCAs with $T_{\mathrm{m}}>2000^{\circ} \mathrm{C}$, or multi-phase RCCAs with $T_{\mathrm{s}}>1100^{\circ} \mathrm{C}$ and the secondary-phase volume fraction $\geq 20 \%$ at $1000^{\circ} \mathrm{C}$, have better ability to retain high strength at $1000^{\circ} \mathrm{C}$.

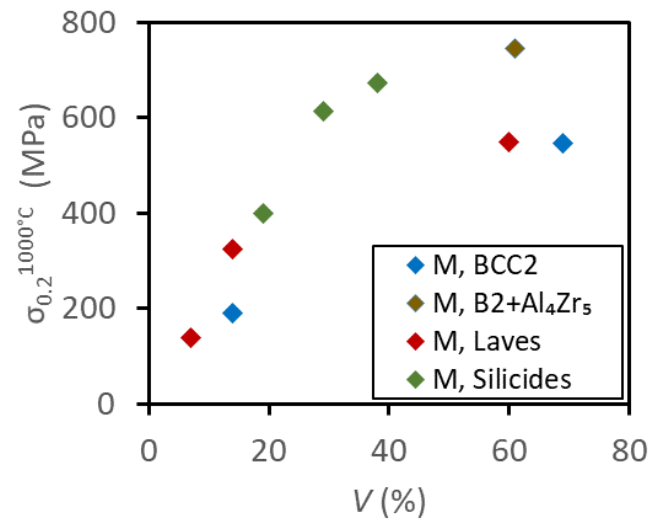

(a)

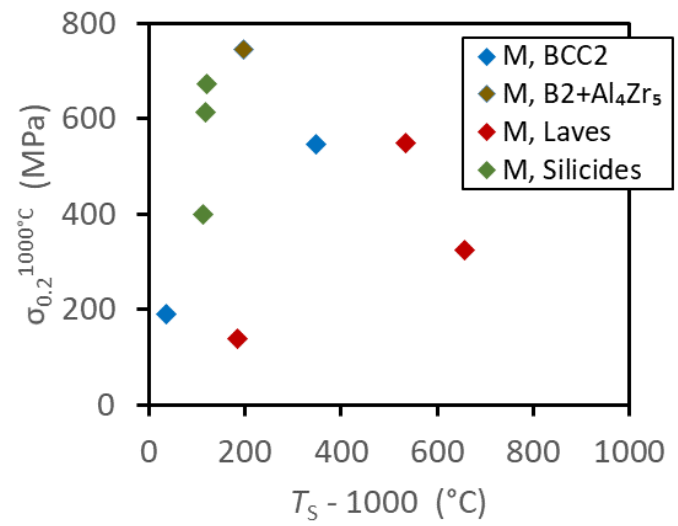

(b)

Figure 5. The yield strength $\left(\sigma_{0.2}{ }^{1000^{\circ} \mathrm{C}}\right)$ of the multi-phase $(\mathrm{M})$ RCCAs with different secondary phases as a function of (a) the volume fraction $V$ of the secondary phases at $1000^{\circ} \mathrm{C}$ and (b) the temperature difference between the solvus $\left(T_{\mathrm{s}}\right)$ and testing $\left(1000^{\circ} \mathrm{C}\right)$ temperatures.

\section{Behavior of RCCAs at $1200^{\circ} \mathrm{C}$}

All but one of the $15 \mathrm{RCCAs}$ that are reported to be single-phase $\mathrm{BCC}$ at $25^{\circ} \mathrm{C}$ have $T_{\mathrm{s}}<1200^{\circ} \mathrm{C}$ and are therefore thermodynamically stable single-phase structures at $1200^{\circ} \mathrm{C}$. The exception is $\mathrm{Al}_{0.4} \mathrm{Hf}_{0.5} \mathrm{NbTaTiZr}$, which, in accord to CALPHAD calculations, has a $\mathrm{BCC} 1+\mathrm{BCC} 2$ structure at $1200^{\circ} \mathrm{C}$. Among the $11 \mathrm{RCCAs}$ reported to be multi-phase at $25^{\circ} \mathrm{C}, \mathrm{Al}_{0.24} \mathrm{NbTiVZr}$, $\mathrm{Cr}_{0.3} \mathrm{NbTiZr}$, MoNbTiVZr and NbTaTiVZr become single-phase BCC structures at $1200^{\circ} \mathrm{C}$ and the other 7 alloys retain their multi-phase structure. The dependence of the yield strength at $1200^{\circ} \mathrm{C}\left(\sigma_{0.2^{1200^{\circ}} \mathrm{C}}\right)$ on $T_{\mathrm{m}}$ for the single-phase and multi-phase RCCAs is shown in Figure 6a. There is a general trend for $\sigma_{0.2}{ }^{1200^{\circ} \mathrm{C}}$ of the RCCAs that are single-phase structures at $1200^{\circ} \mathrm{C}$ to increase with increasing $T_{\mathrm{m}}$; however 3 alloys with moderate $T_{\mathrm{m}}$ values, $\operatorname{AlCrMoTi}\left(T_{\mathrm{m}}=\right.$ $\left.1876^{\circ} \mathrm{C}\right)$, HfNbTaTiZr $\left(T_{\mathrm{m}}=1882^{\circ} \mathrm{C}\right)$ and $\operatorname{HfMo}_{0.5} \operatorname{NbTiV}_{0.5}\left(T_{\mathrm{m}}=1987^{\circ} \mathrm{C}\right)$, have $\sigma_{0.2^{1200}}{ }^{\circ} \mathrm{C}$ less than $100 \mathrm{MPa}$, which is typical for alloys with $T_{\mathrm{m}}<1750^{\circ} \mathrm{C}$. The overall trend of $\sigma_{0.2}{ }^{1200^{\circ} \mathrm{C}}$ with 
$T_{\mathrm{m}}$ can be described by a band:

$$
\sigma_{0.2}^{1200^{\circ} \mathrm{C}}=0.625\left(T_{\mathrm{m}}-T_{\mathrm{B}}\right)
$$

where $T_{\mathrm{B}}$ is in the range from $1100^{\circ} \mathrm{C}$ to $1700^{\circ} \mathrm{C}$ (Figure 6a).

The $\sigma_{0.2}{ }^{1200^{\circ} \mathrm{C}}$ values of the multi-phase RCCAs are similar to those of the single-phase RCCAs with the same (low) $T_{\mathrm{m}}$ values (Figure 6a). Therefore, multi-phase RCCAs have considerably lower strength than many single-phase RCCAs with higher $T_{\mathrm{m}}$.

Softening behavior in the temperature range between $1000^{\circ} \mathrm{C}$ and $1200^{\circ} \mathrm{C}$ of the studied RCCAs with different $T_{\mathrm{m}}$ values is shown in Figure 6b. There are two groups of single-phase RCCAs with different dependence of the strength drop $\eta_{2}=\sigma_{0.2}{ }^{1200^{\circ} \mathrm{C}} / \sigma_{0.2}{ }^{1000^{\circ} \mathrm{C}}$ on $T_{\mathrm{m}}$. In the first group, which includes AlMoNbTi, HfNbTaTiZr, HfMoNbTiZr, AlCrMoTi and $\mathrm{HfMo}_{0.5} \mathrm{NbTiV}_{0.5}, \eta_{2}$ decreases (from 0.372 to 0.163 ) with increasing $T_{\mathrm{m}}$ (from $1711^{\circ} \mathrm{C}$ to $1987^{\circ} \mathrm{C}$ ). In the second group, which includes all other single-phase RCCAs, $\eta_{2}$ increases with increasing $T_{\mathrm{m}}$. The 'anomalous' behavior of the stress ratio $\eta_{2}$ for the first group of the single-phase RCCAs can be explained if the presence of non-equilibrium secondary phases (BCC2 in the three Hf-containing and A15 in two Al-containing RCCAs), which precipitate during heating and holding at $1200^{\circ} \mathrm{C}$, is assumed. Although $T_{\mathrm{s}}$ for these alloys is smaller than the testing temperature $\left(1200^{\circ} \mathrm{C}\right)$, the secondary phases may remain at $1200^{\circ} \mathrm{C}$ due to insufficient diffusion kinetics and cause additional strengthening. In this case, a higher volume fraction of a residual secondary phase is expected for an alloy with smaller $\Delta T=\left(1200^{\circ} \mathrm{C}-T_{\mathrm{s}}\right)$. Indeed, $\sigma_{0.2}{ }^{1200^{\circ} \mathrm{C}} / \sigma_{0.2}{ }^{1000^{\circ} \mathrm{C}}$ increases with decreasing $\Delta T$ for these 5 RCCAs (Figure 6c).

The multi-phase RCCAs do not show any dependence of $\sigma_{0.2}{ }^{1200^{\circ} \mathrm{C}} / \sigma_{0.2}{ }^{1000^{\circ} \mathrm{C}}$ on $T_{\mathrm{m}}$ (Figure $6 \mathrm{~b}$ ). However, their strength drop relates directly to the decrease in the volume fraction of the secondary phases (Figure 6d). 

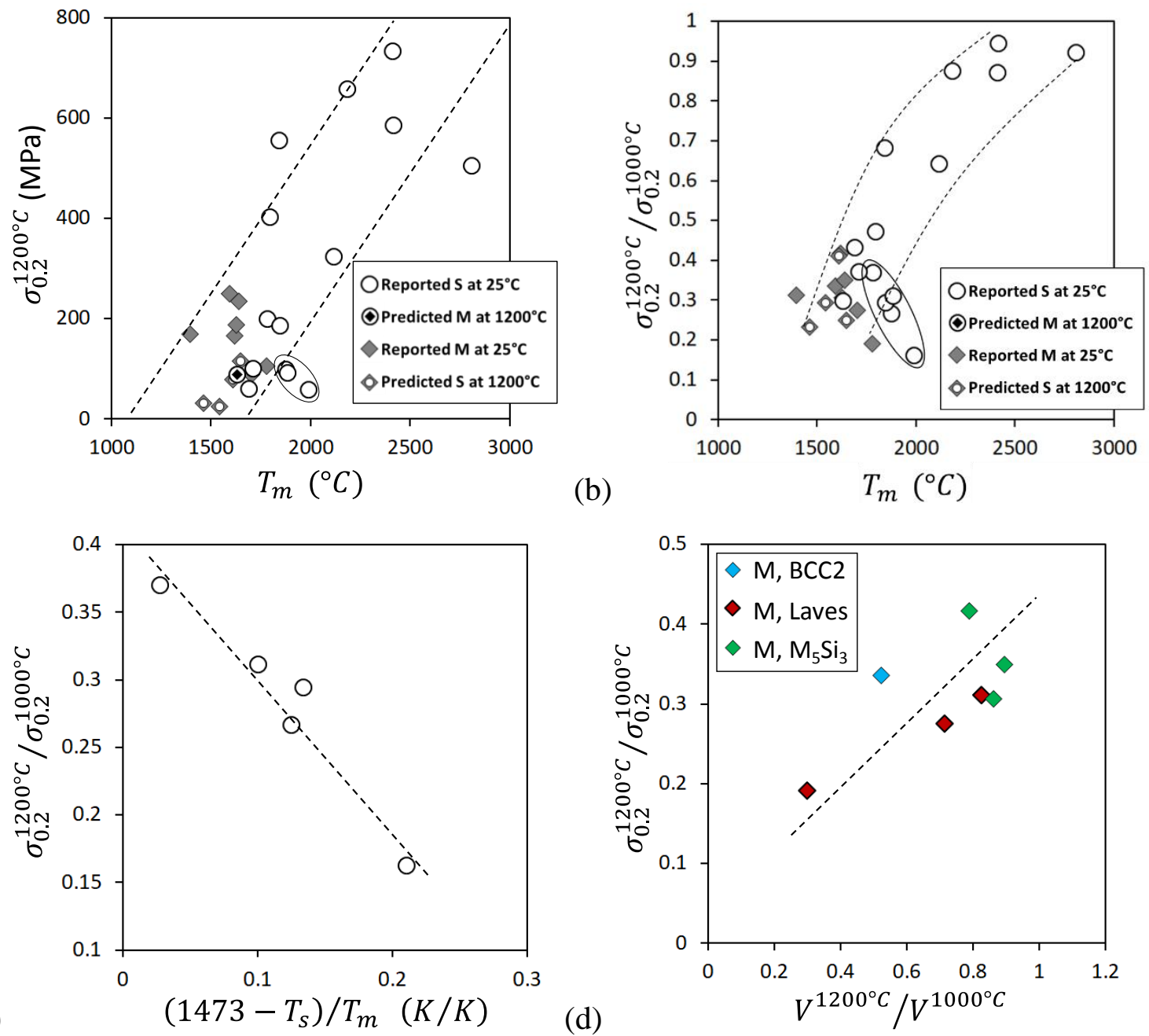

Figure 6. (a) Yield strength at $1200^{\circ} \mathrm{C}\left(\sigma_{0.2}{ }^{1200^{\circ} \mathrm{C}}\right)$ and (b-d) yield strength ratio $\left(\sigma_{0.2}{ }^{1200^{\circ} \mathrm{C}} / \sigma_{0.2} 1000^{\circ} \mathrm{C}\right)$ of single-phase $(\mathrm{S})$ and multi-phase $(\mathrm{M})$ RCCAs as a function of $(\mathrm{b})$ the melting temperature $T_{\mathrm{m}}$ or (c) the difference between testing $(1473 \mathrm{~K})$ and equilibrium solvus $\left(T_{\mathrm{s}}\right)$ temperatures (for five single-phase alloys showing 'anomalous' dependence on $T_{\mathrm{m}}$ ) normalized by $T_{\mathrm{m}}$ or $(\mathrm{d})$ the volume fraction ratio $\left(V^{1200^{\circ} \mathrm{C}} / V^{1000^{\circ} \mathrm{C}}\right)$ of the secondary phases in multi-phase RCCAs. The bubble in (a) represents the three off-trend alloys, i.e. HfNbTaTiZr, AlCrMoTi and $\mathrm{HfMo}_{0.5} \mathrm{NbTiV}_{0.5}$. The bubble in (b) shows the five reverse-trend alloys, i.e. AlMoNbTi and HfMoNbTiZr in addition to the three previous ones in (a).

\section{DISCUSSION}

\subsection{Influence of the $\boldsymbol{T}_{\mathrm{m}}$ on the Temperature Dependence of RCCA Yield Strength}

Both the CALPHAD calculations and ROM analysis show that the reported single-phase RCCAs have a wide spread in $T_{\mathrm{m}}$ ranging, according to CALPHAD, from $1632^{\circ} \mathrm{C}$ for $\mathrm{Al}_{0.4} \mathrm{Hf}_{0.6} \mathrm{NbTaTiZr}$ to $2807^{\circ} \mathrm{C}$ for MoNbTaW. The $T_{\mathrm{m}}$ range of the reported multi-phase RCCAs is much narrower, from $1397^{\circ} \mathrm{C}$ for $\mathrm{CrMo}_{0.5} \mathrm{NbTa}_{0.5} \mathrm{TiZr}$ to $1780^{\circ} \mathrm{C}$ for $\mathrm{AlCrMoNbTi}$. Formation of secondary 
phases during solidification is associated with considerably lower $T_{\mathrm{m}}$ values.

Single-phase RCCAs show RT yield strength values, $\sigma_{0.2}{ }^{25^{\circ} \mathrm{C}}$, in the range from $880 \mathrm{MPa}$ to 1790 $\mathrm{MPa}$. No clear relationship is found between $\sigma_{0.2}{ }^{25^{\circ} \mathrm{C}}$ and $T_{\mathrm{m}}$ or $\delta_{\mathrm{r}}$ for the reported RCCAs. This agrees with recent work by Rao et al. [24, 25] who used atomistic simulations and the Suzuki model to calculate the yield strengths of 3 ternary and 9 quaternary BCC RCCAs. They showed that the solid solution strengthening of these alloys at temperatures where diffusion processes are not active, including room temperature, is likely controlled by the stacking fault energy fluctuations along screw dislocations rather than by the atomic radius or shear modulus misfits. These stacking fault energy fluctuations cause significant barriers for kink migration and for dragging edge dislocation dipoles produced by kink collisions along the screw dislocations. The solute-dislocation interaction energies are composition dependent, which explains large variations in the RT yield strengths for the single-phase RCCAs (Figure 3a). In addition to solidsolution strengthening, multi-phase RCCAs are also strengthened by secondary phases. As a result, $\sigma_{0.2}{ }^{25^{\circ} \mathrm{C}}$ of multi-phase RCCAs tends to increase with increasing $V$, and alloys with $V \geq$ $40 \%$ are generally stronger than single-phase RCCAs.

Other strengthening mechanisms, such as grain boundary (Hall-Petch) or dislocation forest strengthening provide second-order effects on yield strength. All the studied alloys have coarsegrained structures, with the average grain size exceeding $100 \mu \mathrm{m}$. Taking a typical value of 400 $\mathrm{MPa} \mu \mathrm{m}^{-0.5}$ for the Hall-Petch constant $\mathrm{k}_{\sigma}$ [8], the contribution of the grain size $d$ to the yield strength is $\sim 40 \mathrm{MPa}$ or $28 \mathrm{MPa}$ when $\mathrm{d}=100 \mu \mathrm{m}$ or $200 \mu \mathrm{m}$, which is negligible compared to the reported yield strength values. Recent analysis of the Hall-Petch effect on a classical refractory HEA HfNbTaTiZr resulted in $\mathrm{k}_{\sigma}=270 \mathrm{MPa}_{\mu \mathrm{m}}^{-0.5}$ [10]. This value of the Hall-Petch constant gives even smaller strengthening contribution from grain boundaries, only $27 \mathrm{MPa}$ at d $=100 \mu \mathrm{m}$. The contribution to the yield strength from forest dislocations is also low $(<50 \mathrm{MPa})$ as the dislocation density in HIP+A, A or AC conditions is low $\left(\leq 10^{12} \mathrm{~m}^{-2}\right)$. Strong texture is generally formed after extensive deformation and it is not typical in cast and annealed alloys. Microsegregation may affect local microhardnes, but the macroscopic strength is generally unaffected. Thus, the strengths of the reported RCCAs are largely controlled by dislocation/solute and dislocation/precipitate interactions.

The solid solution strengthening model by Rao et al. [24, 25] does not take into account diffusion effects and it agrees well with the experimental data only at relatively low temperatures, where 
diffusion-controlling deformation mechanisms can be ignored. Earlier analysis of the deformation behavior of a HfNbTaTiZr RCCA showed at least two strengthening mechanisms: (i) thermally-activated, diffusionless dislocation glide (similar to that described above) at low temperatures and (ii) diffusion-controlled dislocation climb/glide at high temperatures [26]. The diffusion-controlled regime generally occurs above $\sim 0.5-0.6 T_{\mathrm{m}}$ and can be distinguished from the low-temperature regime by a more rapid drop in strength with increasing temperature, because dislocations are able to move more easily around obstacles [27, 28]. To identify the location of this transition in the studied RCCAs, their $\log \left(\sigma_{0.2}\right)$ values are plotted versus $T / T_{\mathrm{m}}$ in Figure $7 \mathrm{a}$ and Figure $7 \mathrm{~b}$ for the single-phase and multi-phase RCCAs, respectively. The strength data for additional temperatures, taken from [6] or obtained by the authors, are also shown for several alloys to better identify the transition. For comparison, curves are shown in Figure 7a for commercial alloys based on Mo (TZM) and $\mathrm{Nb}$ (C-103), and for pure tungsten.

Two temperature regions, with very different temperature dependence of the yield strength, are clearly seen. The transition from the low-temperature regime to the high-temperature regime is manifested by a stronger decrease in the yield strength with increasing temperature. All the single-phase RCCAs show the transition at almost the same homologous temperature of $\sim 0.6 T_{\mathrm{m}}$ (Figure 7a). In seven single-phase RCCAs, which have $T_{\mathrm{m}}<2121 \mathrm{~K}\left(1848^{\circ} \mathrm{C}\right)$, this transition occurs below $1000^{\circ} \mathrm{C}$. In four single-phase RCCAs, with $T_{\mathrm{m}}$ between 2143 and $2393 \mathrm{~K}$ (1870 and $2120^{\circ} \mathrm{C}$ ), it occurs between $1000^{\circ} \mathrm{C}$ and $1200^{\circ} \mathrm{C}$. Only four remaining single-phase RCCAs (MoNbTaW, MoNbTaTiW, MoNbTaVW and MoNbTaTiVW) for which $T_{\mathrm{m}} \geq 2455 \mathrm{~K}\left(2182^{\circ} \mathrm{C}\right)$ show transition to the diffusion-controlling regime at temperatures $\geq 1200^{\circ} \mathrm{C}$. Since $\sigma_{0.2}$ drops more quickly with increasing $T / T_{\mathrm{m}}$ in the diffusion-controlled regime than in the glidecontrolling regime, this explains why the single-phase RCCAs with higher $T_{\mathrm{m}}$ are generally stronger at $1000^{\circ} \mathrm{C}$ and $1200^{\circ} \mathrm{C}$. For comparison, the transition to the high-temperature regime in pure tungsten occurs at $\sim 0.45 T_{\mathrm{m}}\left(1371^{\circ} \mathrm{C}\right)$ and in TZM and C-103 at $\sim 0.55 T_{\mathrm{m}}\left(1300^{\circ} \mathrm{C}\right.$ and $1090^{\circ} \mathrm{C}$, respectively) and these conventional materials have noticeably lower strength than many studied RCCAs at equivalent $T / T_{\mathrm{m}}$ (Figure $7 \mathrm{a}$ ). A clear advantage of the RCCAs relative to the conventional refractory alloys can be seen: RCCAs are stronger and they have higher hightemperature capability.

The strength of multi-phase RCCAs is mainly controlled by solid-solution, precipitation and dispersoid strengthening, with contributions from other strengthening mechanisms assessed to be 
small. The transition to the high-temperature, diffusion-controlled regime occurs in these alloys in a rather wide temperature interval of $\sim 0.56-0.7 T_{\mathrm{m}}$ (Figure $7 \mathrm{~b}$ ). Because the reported multiphase RCCAs have relatively low $T_{\mathrm{m}}$, not exceeding $1780^{\circ} \mathrm{C}$, the effect from solid solution strengthening is lost at temperatures considerably lower than in many single-phase RCCAs with higher $T_{\mathrm{m}}$. For example, $0.6 T_{\mathrm{m}}$ represents temperatures below $1000^{\circ} \mathrm{C}$ for all the studied multiphase RCCAs. However, precipitation and dispersoid strengthening can be noticeable at temperatures as high as $\sim 0.7 T_{\mathrm{m}}$ for alloys that have $T_{\mathrm{s}} \geq 0.75 T_{\mathrm{m}}$ or which are multi-phase at $T_{\mathrm{m}}$. The high-temperature strength of these RCCAs is generally lost when the volume fraction of the secondary phases becomes less than $\sim 20 \%$. This analysis suggests that multi-phase RCCAs with high $T_{\mathrm{s}}$ and $T_{\mathrm{m}}$ would be better candidates for high-temperature applications (at $T<T_{\mathrm{s}}$ ) than single-phase RCCAs with the same $T_{\mathrm{m}}$.

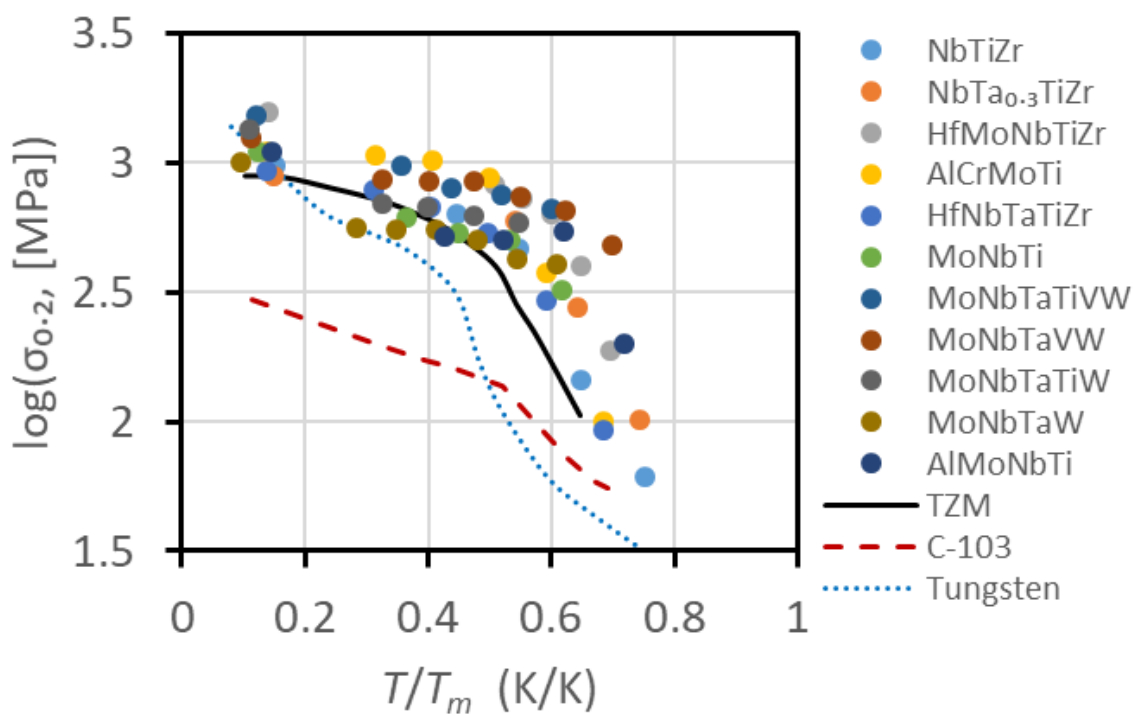

(a) 


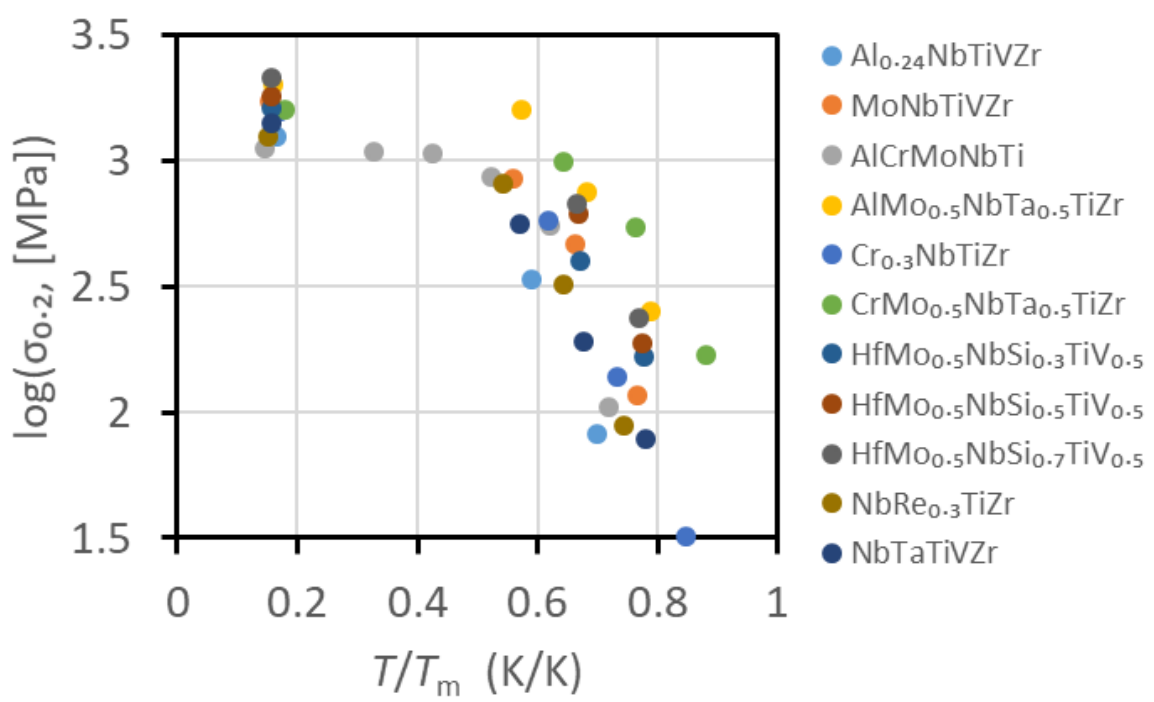

(b)

Figure 7. Plots of $\log \left(\sigma_{0.2}\right) v s T / T_{\mathrm{m}}$ for (a) RCCAs reported to be single-phase $\mathrm{BCC}$ at $25^{\circ} \mathrm{C}$ and (b) RCCAs reported to be multi-phase at $25^{\circ} \mathrm{C}$. For comparison, curves are shown in figure $7(\mathrm{a})$ for W [29] and for commercial refractory alloys TZM (a Mo-based alloy) [30] and C-103 (a Nbbased alloy) [31].

\subsection{Future Development of High Temperature RCCAs}

In the process of improving the properties of RCCAs at high temperatures, two main strategies can be proposed from the above analysis. One strategy is to develop single-phase solid solution RCCAs with high melting temperatures. This approach is based on the observed tendency for the single-phase RCCAs (i) to increase their high-temperature strength with increasing $T_{\mathrm{m}}$ and (ii) to have higher $T_{\mathrm{m}}$ than multi-phase RCCAs. To explore the high $T_{\mathrm{m}}$ single-phase strategy, the variation in $T_{\mathrm{m}}$ values for the vast number of alloying possibilities is estimated using the rule of mixtures (ROM) corrected by an empirical relationship found between $T_{\mathrm{m}}{ }^{\text {ROM }}$ and $T_{\mathrm{m}}{ }^{\text {CALPHAD }}$, i.e. $T_{m}=4\left(T_{m}^{R O M}-807\right) / 3$ (Fig.2). Figure 8 shows $T_{\mathrm{m}}$ as a function of density for equimolar mixtures of 455 ternaries, 1372 quaternaries, 3003 quinaries and 5005 senaries combinations pulled from a panel of 15 elements including $\mathrm{Al}, \mathrm{Co}, \mathrm{Cr}, \mathrm{Fe}, \mathrm{Hf}, \mathrm{Mo}, \mathrm{Nb}, \mathrm{Ni}, \mathrm{Re}, \mathrm{Si}, \mathrm{Ta}, \mathrm{Ti}, \mathrm{V}$, $\mathrm{W}$ and $\mathrm{Zr}$. There are two main trends. One is an averaging trend on the barycenter of the scatterplot $\left(\rho=9.6 \mathrm{~g} / \mathrm{cm}^{3}\right.$ and $\left.T_{\mathrm{m}}=1666^{\circ} \mathrm{C}\right)$ as the number of principal elements increases. The second is the increase of $T_{\mathrm{m}}$ with increasing density. From the 9835 possible equimolar mixtures of principal elements, 1804 can potentially have $T_{\mathrm{m}}$ above $2000^{\circ} \mathrm{C}$. These 1804 high melting temperature alloys have densities in the range from 8 to $19 \mathrm{~g} / \mathrm{cm}^{3}$ with a mean value of 12.3 
$\mathrm{g} / \mathrm{cm}^{3}$. Thus, single-phase RCCAs with higher $T_{\mathrm{m}}$ will also have higher alloy density.

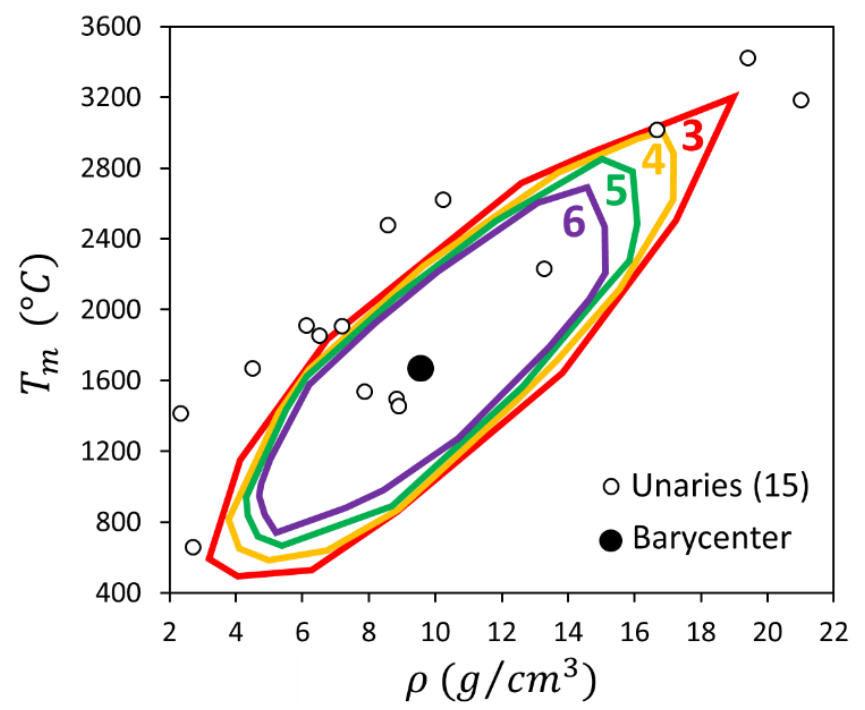

Figure 8: Contour lines bounding the melting temperature as a function of density for all possible equimolar combinations of 3, 4, 5 and 6 elements from a palette of 15 elements including Al, Co, $\mathrm{Cr}, \mathrm{Fe}, \mathrm{Hf}, \mathrm{Mo}, \mathrm{Nb}, \mathrm{Ni}, \mathrm{Re}, \mathrm{Si}$, Ta, Ti, V, W and $\mathrm{Zr}$. The averaging effect of increasing the number of principal elements shrinks the ranges in densities and melting temperatures toward $\rho$ $=9.6 \mathrm{~g} / \mathrm{cm}^{3}$ and $T_{\mathrm{m}}=1666^{\circ} \mathrm{C}$ (black dot).

Alloy density is an important material constant for alloys used in flight applications and alloys with high specific strength (high strength to density ratio) are preferable for reducing weight and fuel consumption and decreasing environmental pollution. Conventional refractory alloys have high density, generally noticeably higher than other structural metals, contributing to limited use in aerospace structures. On the other hand, recently developed RCCAs have a wide range of densities, varying from 5.6 to $14 \mathrm{~g} / \mathrm{cm}^{3}$. Higher density single-phase RCCAs generally have higher $T_{\mathrm{m}}$; thus, in accord to this work, they should be stronger at high temperatures. It would therefore be interesting to compare the high temperature strengths of RCCAs having different densities and to identify how alloy density affects the specific yield strength of RCCAs at different temperatures.

Figure 9a shows $\sigma_{0.2}$ at $25^{\circ} \mathrm{C}$ of single-phase and multi-phase RCCAs as a function of alloy density. Only single-phase alloys have densities of $10 \mathrm{~g} / \mathrm{cm}^{3}$ or higher. The peak $\sigma_{0.2}{ }^{25^{\circ} \mathrm{C}}$ values, exceeding $2000 \mathrm{MPa}$, are reported for multi-phase RCCAs having densities of $\sim 7-8 \mathrm{~g} / \mathrm{cm}^{3}$. $\sigma_{0.2}{ }^{25^{\circ} \mathrm{C}}$ decreases rapidly with decreasing $\rho$ below $7 \mathrm{~g} / \mathrm{cm}^{3}$ or with increasing $\rho$ above $8 \mathrm{~g} / \mathrm{cm}^{3}$, 
approaching $\sigma_{0.2^{25^{\circ}} \mathrm{C}} \sim 1000 \mathrm{MPa}$ for both low-density $\left(\sim 6 \mathrm{~g} / \mathrm{cm}^{3}\right)$ and high density $\left(\sim 14 \mathrm{~g} / \mathrm{cm}^{3}\right)$ RCCAs. The specific yield strength, $\sigma_{0.2}{ }^{25^{\circ} \mathrm{C}} / \rho$, is in the range from $\sim 150$ to $280 \mathrm{MPa} \mathrm{cm} / \mathrm{g}$ for low-density $\left(<8 \mathrm{~g} / \mathrm{cm}^{3}\right) \mathrm{RCCAs}$ and it decreases almost linearly to $\sigma_{0.2}{ }^{25^{\circ} \mathrm{C}} / \rho=70 \mathrm{MPa} \mathrm{cm} / \mathrm{g}$ with increasing $\rho$ to $14 \mathrm{~g} / \mathrm{cm}^{3}$.

At $1000^{\circ} \mathrm{C}$, RCCAs with densities less than $10 \mathrm{~g} / \mathrm{cm}^{3}$ do not show clear dependence of $\sigma_{0.2^{1000}}{ }^{\circ} \mathrm{C}$ and $\sigma_{0.2}{ }^{1000^{\circ} \mathrm{C}} / \rho$ on $\rho$ (Figure $9 \mathrm{~b}$ ), although the specific strength of some multi-phase RCCAs seem to be superior to single-phase RCCAs. RCCAs within this density range have $\sigma_{0.2} 1000^{\circ} \mathrm{C}$ from $\sim 80$ to $800 \mathrm{MPa}$ and $\sigma_{0.2}{ }^{1000^{\circ} \mathrm{C}} / \rho$ from 11 to $105 \mathrm{MPa} \mathrm{cm} / \mathrm{g}$. With an increase in $\rho$ from 10 to $14 \mathrm{~g} / \mathrm{cm}^{3}, \sigma_{0.2}{ }^{1000^{\circ} \mathrm{C}}$ decreases from $845 \mathrm{MPa}$ to $540 \mathrm{MPa}$ and $\sigma_{0.2}{ }^{1000^{\circ} \mathrm{C}} / \rho$ decreases from 85 to $40 \mathrm{MPa} \mathrm{cm} / \mathrm{g}$. One can see that high specific strength at $25^{\circ} \mathrm{C}$ and $1000^{\circ} \mathrm{C}$ is expected from medium density $\left(\sim 6.5-9 \mathrm{~g} / \mathrm{cm}^{3}\right)$ RCCAs.

The behavior at $1200^{\circ} \mathrm{C}$ is dramatically different (Figure 9c). Here a clear tendency is seen for $\sigma_{0.2}{ }^{1200^{\circ} \mathrm{C}}$ to increase with increasing $\rho$ until a peak strength of $735 \mathrm{MPa}$ is achieved at $\rho=12.3$ $\mathrm{g} / \mathrm{cm}^{3}$ for MoNbTaVW. The $\sigma_{0.2}{ }^{1200^{\circ} \mathrm{C}} / \rho$ values for RCCAs with $\rho \geq 10 \mathrm{~g} / \mathrm{cm}^{3}$ are noticeably higher than for the lower density RCCAs at this temperature. This trend is likely related to the observation that single-phase RCCAs with the highest density (e.g. those containing W) also have the highest $T_{\mathrm{m}}$ values and that $\sigma_{0.2}{ }^{1200^{\circ} \mathrm{C}}$ increases with $T_{\mathrm{m}}$ faster than the density (Table 1 , Table 2, Figure 6b).
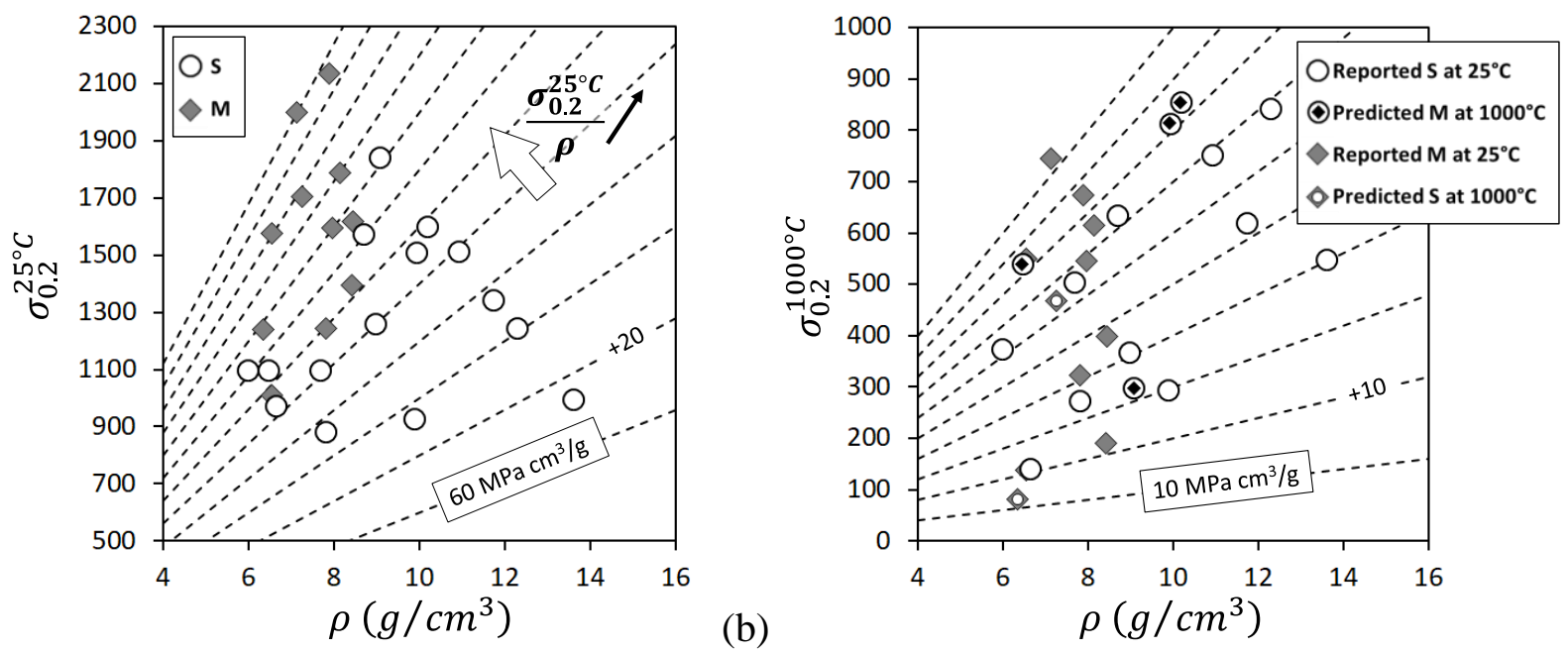


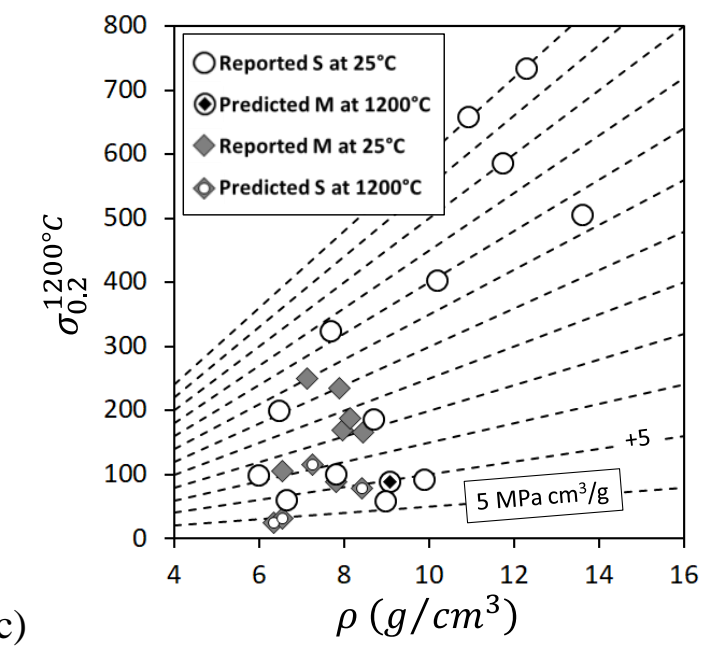

Figure 9. $(\mathrm{a}, \mathrm{b}, \mathrm{c})$ Yield strength $\left(\sigma_{0.2}\right)$ of single-phase $(\mathrm{S})$ and multi-phase $(\mathrm{M})$ RCCAs at (a) $25^{\circ} \mathrm{C}$, (b) $1000^{\circ} \mathrm{C}$ and (c) $1200^{\circ} \mathrm{C}$ as a function of alloy density. The dashed performance index lines give constant values of the yield strength to density ratio (specific yield strength). The arrow shows the increase in specific yield strength from the bottom-right to the top-left. The corresponding value of the specific yield strength is shown on the first performance line, and the increment of the specific yield strength between the nearest lines is shown on the second line. Materials with higher performance indeces have higher values of the specific yield strength.

The second design strategy for high temperature RCCAs relies on developing multi-phase RCCAs with both high $T_{\mathrm{s}}$ and $T_{\mathrm{m}}$. This approach is based on the observation that below $T_{\mathrm{s}}$ multiphase RCCAs generally have higher strength than many single-phase RCCAs, even if their melting temperature is lower and $T_{\mathrm{s}} / T_{\mathrm{m}}>0.6$. The basic idea is to distribute a high volume fraction of a hard ordered phase, which provides the high temperature strength, in a soft disordered solid solution matrix, which provides the room temperature ductility. Exploring this concept is much more difficult than the previous because it requires prediction of the extent of the solvus in composition and temperature space. There is no simple relationship or correlation that can be used to estimate $T_{\mathrm{s}}$ as a function of composition. Accurate thermodynamic descriptions of the Gibbs free energies are needed that are not being met for high order concentrated mixtures of refractory elements mainly because important intermetallic phases, e.g ordered bcc structures (B2, $\mathrm{L}_{1}$ and $\mathrm{DO}_{3}$ ), have no models in refractory alloys. While thermodynamic databases are slowly being improved, innovative approaches should be explored to more rapidly overcome the limitations of current CALPHAD databases. To this respect, the diffusion of artificial intelligence (data-mining and machine learning) in the field of thermodynamic, metallurgy and alloy design represents a great opportunity to anticipate the 
stability of phases of interests in high dimensionality composition and temperature space, and point out where to focus experimental effort.

\section{SUMMARY AND CONCLUSIONS}

The objective of the present work is to explore origins of the temperature dependent decrease in the yield strength of refractory complex concentrated alloys (RCCAs) at elevated temperatures. Correlations are considered between compressive yield strengths and microstructure (singlephase alloys are compared with multi-phase alloys), alloy melting temperature (taken as the solidus temperature, $\left.T_{\mathrm{m}}\right)$, solvus temperature $\left(T_{\mathrm{s}}\right)$ and volume fraction of secondary phases $(V)$, and an atom misfit parameter $\left(\delta_{\mathrm{r}}\right)$ in multi-phase RCCAs.

The reported single-phase RCCAs show a wide spread in $T_{\mathrm{m}}$ ranging from $1632^{\circ} \mathrm{C}$ for $\mathrm{Al}_{0.4} \mathrm{Hf}_{0.6} \mathrm{NbTaTiZr}$ to $2807^{\circ} \mathrm{C}$ for MoNbTaW . The $T_{\mathrm{m}}$ range of multi-phase RCCAs is much narrower, from $1397^{\circ} \mathrm{C}$ for $\mathrm{CrMo}_{0.5} \mathrm{NbTa}_{0.5} \mathrm{TiZr}$ to $1780^{\circ} \mathrm{C}$ for $\mathrm{AlCrMoNbTi}$. Formation of secondary phases during solidification is associated with lower $T_{\mathrm{m}}$ values.

The RT strengths of single-phase and multi-phase RCCAs with volume fractions $V$ of secondary phases less than $40 \%$, are similar and in the range from $880 \mathrm{MPa}$ to $1790 \mathrm{MPa}$. No clear relationship was found between $\sigma_{0.2}{ }^{25^{\circ} \mathrm{C}}$ and $T_{\mathrm{m}}$ or $\delta_{\mathrm{r}}$ for these alloys. The $\sigma_{0.2}{ }^{25^{\circ} \mathrm{C}}$ of multi-phase RCCAs tends to increase with increasing $V$, and alloys with $V \geq 40 \%$ are generally stronger than single-phase RCCAs.

Single-phase and multi-phase RCCAs have a similar spread in $\sigma_{0.2}$, from $80 \mathrm{MPa}$ to $855 \mathrm{MPa}$, at

$1000^{\circ} \mathrm{C} . \sigma_{0.2}{ }^{1000^{\circ} \mathrm{C}}$ of single-phase RCCAs has a tendency to increase with increasing $T_{\mathrm{m}} \cdot \sigma_{0.2}{ }^{1000^{\circ} \mathrm{C}}$ of the multi-phase RCCAs shows no dependence on $T_{\mathrm{m}}$, but it depends on the type of secondary phase and increases with increasing total volume fraction of secondary phases. An increase in $T_{\mathrm{s}}$ of the same type of the secondary phase beyond $1000^{\circ} \mathrm{C}$ increases $\sigma_{0.2}{ }^{1000^{\circ} \mathrm{C}}$.

The drop in strength between $25^{\circ} \mathrm{C}$ and $1000^{\circ} \mathrm{C}$ is more dramatic for the single-phase RCCAs with lower $T_{\mathrm{m}}$ and for multi-phase RCCAs with low volume fraction (<20\%) of secondary phases. Single-phase RCCAs with $T_{\mathrm{m}}>2000^{\circ} \mathrm{C}$, or multi-phase RCCAs with $T_{\mathrm{s}}>1100^{\circ} \mathrm{C}$ and $V$ $\geq 20 \%$ at $1000^{\circ} \mathrm{C}$, have better ability to retain high strength at $1000^{\circ} \mathrm{C}$.

There is a general trend for $\sigma_{0.2}{ }^{1200^{\circ} \mathrm{C}}, \sigma_{0.2}{ }^{1200^{\circ} \mathrm{C}} / \rho$ and $\sigma_{0.2}{ }^{1200^{\circ} \mathrm{C}} / \sigma_{0.2}{ }^{1000^{\circ} \mathrm{C}}$ of RCCAs that are single-phase structures at $1200^{\circ} \mathrm{C}$ to increase with increasing $T_{\mathrm{m}}$. Multi-phase RCCAs have considerably lower $\sigma_{0.2}{ }^{1200^{\circ} \mathrm{C}}$ and $\sigma_{0.2}{ }^{1200^{\circ} \mathrm{C}} / \rho$ than many single-phase RCCAs. Multi-phase 


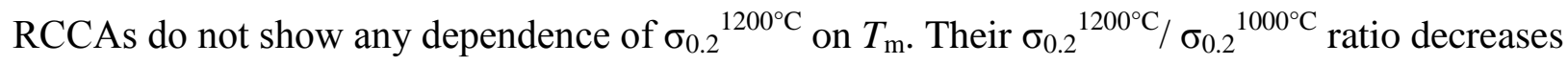
with a decrease in the volume fraction of secondary phases.

The analysis of the temperature dependence of the yield strength suggests that solid-solution strengthening in single-phase BCC RCCAs changes from thermally activated dislocation glide below $0.5-0.6 T_{\mathrm{m}}$ to diffusion-controlled dislocation climb at higher temperatures, which causes a rapid drop in the strength above $\sim 0.6 T_{\mathrm{m}}$. Thus RCCAs with higher $T_{\mathrm{m}}$ experience this drop at higher temperatures.

The strength of the multi-phase RCCAs is controlled by solid-solution, precipitation and dispersoid strengthening. As the reported multi-phase RCCAs have relatively low $T_{\mathrm{m}}$, not exceeding $1780^{\circ} \mathrm{C}$, the effect from solid solution strengthening is lost at temperatures considerably smaller than for many single-phase RCCAs with higher $T_{\mathrm{m}}$. However, precipitation and dispersoid strengthening can be noticeable at temperatures as high as $0.7 T_{\mathrm{m}}$. The hightemperature strength of these RCCAs is generally lost when the volume fraction of the secondary phases becomes less than $\sim 20 \%$. This analysis suggests that multi-phase RCCAs with high $T_{\mathrm{s}}$ and $T_{\mathrm{m}}$ would be better candidates for high-temperature applications (at $T<T_{\mathrm{s}}$ ) than single-phase RCCAs with the same $T_{\mathrm{m}}$.

Single-phase RCCAs with higher $T_{\mathrm{m}}$ generally have higher density. Fortunately, their hightemperature strength (at $T=1200^{\circ} \mathrm{C}$ ) has the tendency to increase with increasing $T_{\mathrm{m}}$ faster than their density. Therefore, the specific strength of the single-phase RCCAs at $1200^{\circ} \mathrm{C}$ increases with increasing density or $T_{\mathrm{m}}$. It is likely that, in order to achieve high specific strength in extreme high-temperature applications, future alloys will have high density, exceeding $10 \mathrm{~g} / \mathrm{cm}^{3}$. The conducted analysis suggests that the loss of high-temperature strength of single-phase BCC RCCAs is likely related to the activation of diffusion-controlled deformation mechanisms, which occurs at $T \geq 0.6$ of the absolute melting temperature $T_{\mathrm{m}}$, and that alloys with higher $T_{\mathrm{m}}$ retain their strength to higher temperatures. On the other hand, a rapid decrease in strength of multiphase RCCAs with increasing temperature above $1000^{\circ} \mathrm{C}$ is probably due to dissolution of secondary phases, which is controlled by the solvus temperature $T_{\mathrm{s}}$ of the phase responsible for precipitation strengthening. The rapid strength drop of these multi-phase alloys above $T_{\mathrm{s}}$, where they become single-phase solid solutions, is related to their $T_{\mathrm{m}}$, similar to single-phase alloys. 


\section{ACKNOWLEDGEMENTS}

Extensive discussion with Dr. S.I. Rao is greatly appreciated. Work by ONS was supported through the Air Force on-site contract FA8650-15-D-5230 managed by UES, Inc., Dayton, Ohio.

\section{REFERENCES}

[1] Senkov ON, Miracle DB, Chaput KJ, Couzinie J-P. Journal of Materials Research 2018;33:3092.

[2] Gorsse S, Miracle DB, Senkov ON. Acta Mater. 2017;135:177.

[3] Gorsse S, Couzinié J-P, Miracle DB. C. R. Physique 2018;19:721.

[4] Senkov ON, Wilks GB, Miracle DB, Chuang CP, Liaw PK. Intermetallics 2010;18:1758.

[5] Senkov ON, Wilks GB, Scott JM, Miracle DB. Intermetallics 2011;19:698.

[6] Couzinié J-P, Senkov ON, Miracle DB, Dirras G. Data in Brief 2018;21:1622.

[7] Gorsse S, Nguyen MH, Senkov ON, Miracle DB. Data in Brief 2018;21:2664.

[8] Cordero ZC, Knight BE, Schuh CA. Int. Mater. Rev. 2016;61:495.

[9] Yoshida S, Ikeuchi T, Bhattacharjee T, Bai Y, Shibata A, Tsuji N. Acta Mater. 2019;171:201.

[10] Chen S, Tseng KK, Tong Y, Li W, Tsai CW, Yeh JW, Liaw PK. J. Alloys Cmpds 2019;795:19.

[11] Mao H, Chen H-L, Chen Q. J. Phase Equilibria and Diffusion 2017;38:353.

[12] Chen H-L, Mao H, Chen Q. Mater. Chem. Phys. 2018;210:279.

[13] CompuTherm Software, Databases. vol. 2018. http://www.computherm.com/index.php?route=product/category\&path=59_83.

[14] Zhang F, Kattner U. Journal of Phase Equilibria and Diffusion 2015;36:1.

[15] Senkov ON, Miller JD, Miracle DB, Woodward C. Calphad: Computer Coupling of Phase Diagrams and Thermochemistry 2015;50:32.

[16] Chou KC, Chang YA. Ber. Bunsenges. Phys. Chem. 1989;93:735.

[17] Wertz K, Miller J, Senkov O. J. Mater. Res. 2018;33:3204.

[18] Gorsse S, Tancret F. J. Mater. Res. 2018;33:2899.

[19] Gorsse S, Senkov ON. Entropy 2018;20:899.

[20] Senkov ON, Woodward C, Miracle DB. JOM 2014;66:2030.

[21] Juan C-C, Tsai M-H, Tsai C-W, Lin C-M, Wang W-R, Yang C-C, Chen S-K, Lin S-J, Yeh J-W. Intermetallics 2015;62:76.

[22] Han ZD, Chen N, Zhao SF, Fan LW, Yang GN, Shao Y, Yao KF. Intermetallics 2017;84:153.

[23] Porter DA, Easterling KE. Phase Transformations in Metals and Alloys. Cheltenham, UK: CRC Press, 1992.

[24] Rao SI, Antillon E, Woodward C, Akdim B, Parthasarathy TA, O.N.Senkov. Scripta Mater. 2019;165:103.

[25] Rao SI, Akdim B, Antillon E, Woodward C, Parthasarathy TA, Senkov ON. Acta Mater. 2019;168:222.

[26] Senkov ON, Scott JM, Senkova SV, Meisenkothen F, Miracle DB, Woodward CF. J. Mater. Sci. 2012;47:4062.

[27] Kuhlmann-Wilsdorf D. Mater. Sci. Eng. A 1989;113:1.

[28] Caillard D, Martin JL. Thermally Activated Mechanisms in Crystal Plasticity. Lausanne, 
Switzeland: Elsevier, 2003.

[29] Schmidt FF, Ogden HR. The Engineering Properties of Tungsten and Tungsten alloys,

DMIC Report 191. Columbus, OH: Battelle Memorial Institute, 1963.

[30] Molibdenum and Molibdenum Alloys. www.molybdenum.com.

[31] ATI Wah Chang Nb Alloy C-103. vol. 2018.

http://www.matweb.com/search/datasheet.aspx?MatGUID=ed50a3a07706450590669cedc77841

50: MatWeb.com. 